\title{
Interventions to increase the use of electronic health information by healthcare practitioners to improve clinical practice and patient outcomes (Review)
}

Fiander M, McGowan J, Grad R, Pluye P, Hannes K, Labrecque M, Roberts NW, Salzwedel DM, Welch V, Tugwell P

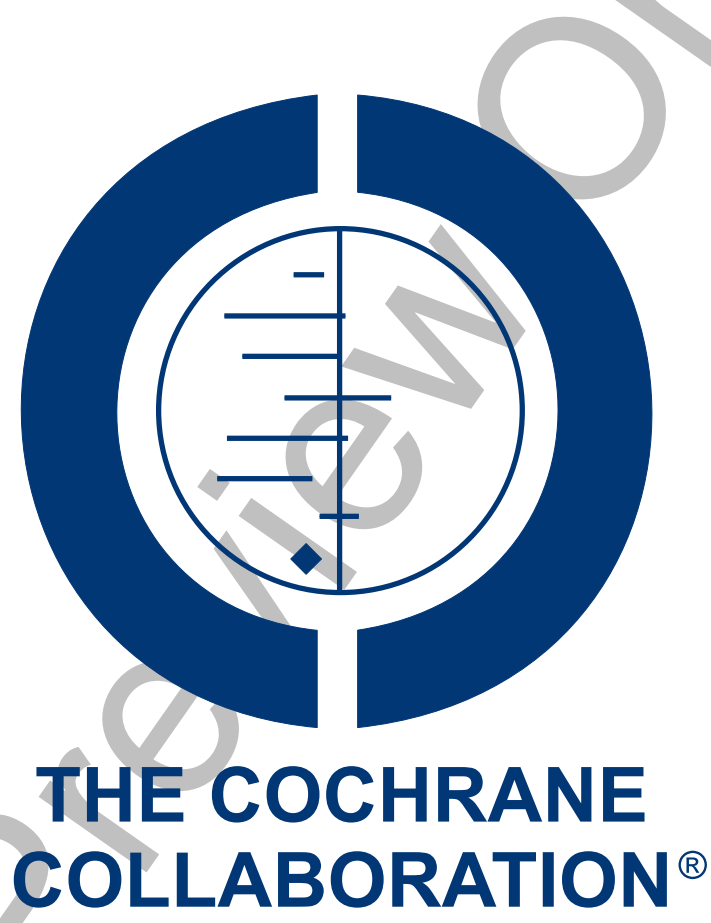

This is a reprint of a Cochrane review, prepared and maintained by The Cochrane Collaboration and published in The Cochrane Library 2015, Issue 3

http://www.thecochranelibrary.com

\section{WILEY}

Interventions to increase the use of electronic health information by healthcare practitioners to improve clinical practice and patient outcomes (Review)

Copyright $\odot 2015$ The Cochrane Collaboration. Published by John Wiley \& Sons, Ltd. 
TABLE OF CONTENTS

HEADER . . . . . . . . . . . . . . . . . . . . . . . . . . . . . . . . . . 1

ABSTRACT . . . . . . . . . . . . . . . . . . . . . . . . . . . . . . . . . . . . . . . . 1

PLAIN LANGUAGE SUMMARY . . . . . . . . . . . . . . . . . . . . . . . . . . . . . . . . . . . .

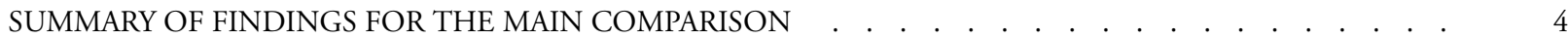

BACKGROUND . . . . . . . . . . . . . . . . . . . . . . . . . . . . . . . . . . . . 5

OBJECTIVES . . . . . . . . . . . . . . . . . . . . . . . . . . . . . . . . . . . . . . . . . . . . .

METHODS . . . . . . . . . . . . . . . . . . . . . . . . . . . . . . . . . . . . . . 5

RESUlTS . . . . . . . . . . . . . . . . . . . . . . . . . . . . . . . . . . . . 8

Figure 1. . . . . . . . . . . . . . . . . . . . . . . . . . . . . . . . . . . . 9

Figure 2. . . . . . . . . . . . . . . . . . . . . . . . . . . . . . . . . . . . . . . . . 11

Figure 3. . . . . . . . . . . . . . . . . . . . . . . . . . . . . . . . . . . . . . 12

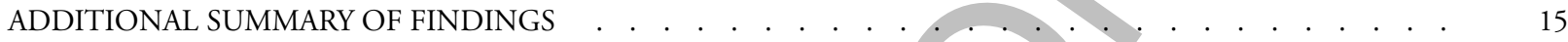

DISCUSSION . . . . . . . . . . . . . . . . . . . . . . . . . . . . . . . . . . . . . . . . . . 19

AUTHORS' CONCLUSIONS . . . . . . . . . . . . . . . . . . . . . . . . . . . . . . . . . . 19

ACKNOWLEDGEMENTS . . . . . . . . . . . . . . . . . . . . . . . . . . . . . . . . . 20

REFERENCES . . . . . . . . . . . . . . . . . . . . . . . . . . . . . . . . . . . . . 20

CHARACTERISTICS OF STUDIES . . . . . . . . . . . . . . . . . . . . . . . . . . . . . . . . . . . . . . . .

DATA AND ANALYSES . . . . . . . . . . . . . . . . . . . . . . . . . . . . . . . . . . . . . . . 46

ADDITIONAL TABLES . . . . . . . . . . . . . . . . . . . . . . . . . . . . . . . . . . . . . . . . . . 4.46

APPENDICES . . . . . . . . . . . . . . . . . . . . . . . . . . . . . . . . . . . . . . . . . . 47

WHAT'S NEW . . . . . . . . . . . . . . . . . . . . . . . . . . . . . . . . . . . . . . 57

HISTORY . . . . . . . . . . . . . . . . . . . . . . . . . . . . . . . . . . 58

CONTRIBUTIONS OF AUTHORS . . . . . . . . . . . . . . . . . . . . . . . . . . . . . . . . . . . . . . . 58

DECLARATIONS OF INTEREST . . . . . . . . . . . . . . . . . . . . . . . . . . . . . . . . . . . . . . . 59

SOURCES OF SUPPORT . . . . . . . . . . . . . . . . . . . . . . . . . . . . . . . . . . . . . . . 59

DIFFERENCES BETWEEN PROTOCOL AND REVIEW . . . . . . . . . . . . . . . . . . . . . . . . . . . 59

Interventions to increase the use of electronic health information by healthcare practitioners to improve clinical practice and patient outcomes (Review)

Copyright $\odot 2015$ The Cochrane Collaboration. Published by John Wiley \& Sons, Ltd. 


\title{
[Intervention Review] \\ Interventions to increase the use of electronic health information by healthcare practitioners to improve clinical practice and patient outcomes
}

\author{
Michelle Fiander ${ }^{1}$, Jessie McGowan ${ }^{2}$, Roland Grad ${ }^{3}$, Pierre Pluye ${ }^{3}$, Karin Hannes ${ }^{4}$, Michel Labrecque ${ }^{5}$, Nia W Roberts ${ }^{6}$, Douglas M \\ Salzwedel ${ }^{7}$, Vivian Welch $^{8}$, Peter Tugwell ${ }^{2}$ \\ ${ }^{1}$ Information Specialist, Consultant, Ottawa, Canada. ${ }^{2}$ Department of Medicine, Faculty of Medicine, University of Ottawa, Ottawa, \\ Canada. ${ }^{3}$ Department of Family Medicine, McGill University, Montreal, Canada. ${ }^{4}$ Methodology of Educational Sciences Research \\ Group, KU Leuven, Leuven, Belgium. ${ }^{5}$ Département de médecine familiale, Université Laval, Centre hospitalier universitaire de Québec \\ - Hôpital St-François d'Assise, Québec, Canada. ${ }^{6}$ Bodleian Health Care Libraries, University of Oxford, Oxford, UK. ${ }^{7}$ Department \\ of Anesthesiology, Pharmacology and Therapeutics, University of British Columbia, Vancouver, Canada. ${ }^{8}$ Bruyère Research Institute, \\ University of Ottawa, Ottawa, Canada \\ Contact address: Michelle Fiander, Information Specialist, Consultant, Ottawa, Ontario, Canada. michelle.fiander@gmail.com.
}

Editorial group: Cochrane Effective Practice and Organisation of Care Group.

Publication status and date: New search for studies and content updated (no change to conclusions), published in Issue 3, 2015.

Review content assessed as up-to-date: 13 November 2013.

Citation: Fiander M, McGowan J, Grad R, Pluye P, Hannes K, Labrecque M, Roberts NW, Salzwedel DM, Welch V, Tugwell P. Interventions to increase the use of electronic health information by healthcare practitioners to improve clinical practice and patient outcomes. Cochrane Database of Systematic Reviews 2015, Issue 3. Art. No.: CD004749. DOI: 10.1002/14651858.CD004749.pub3.

Copyright (C) 2015 The Cochrane Collaboration. Published by John Wiley \& Sons, Ltd.

\section{A B S T R A C T}

\section{Background}

There is a large volume of health information available, and, if applied in clinical practice, may contribute to effective patient care. Despite an abundance of information, sub-optimal care is common. Many factors influence practitioners' use of health information, and format (electronic or other) may be one such factor.

\section{Objectives}

To assess the effects of interventions aimed at improving or increasing healthcare practitioners' use of electronic health information (EHI) on professional practice and patient outcomes.

\section{Search methods}

We searched The Cochrane Library (Wiley), MEDLINE (Ovid), EMBASE (Ovid), CINAHL (EBSCO), and LISA (EBSCO) up to November 2013. We contacted researchers in the field and scanned reference lists of relevant articles.

\section{Selection criteria}

We included studies that evaluated the effects of interventions to improve or increase the use of EHI by healthcare practitioners on professional practice and patient outcomes. We defined EHI as information accessed on a computer. We defined 'use' as logging into EHI. We considered any healthcare practitioner involved in patient care. We included randomized, non-randomized, and cluster randomized controlled trials (RCTs, NRCTs, CRCTs), controlled clinical trials (CCTs), interrupted time series (ITS), and controlled before-and-after studies (CBAs). The comparisons were: electronic versus printed health information; EHI on different electronic devices (e.g. desktop, laptop or tablet computers, etc.; cell / mobile phones); EHI via different user interfaces; EHI provided with or without an educational or training component; and EHI compared to no other type or source of information.

Interventions to increase the use of electronic health information by healthcare practitioners to improve clinical practice and patient outcomes (Review)

Copyright $\odot 2015$ The Cochrane Collaboration. Published by John Wiley \& Sons, Ltd. 


\section{Data collection and analysis}

Two review authors independently extracted data and assessed the risk of bias for each study. We used GRADE to assess the quality of the included studies. We reassessed previously excluded studies following our decision to define logins to EHI as a measure of professional behavior. We reported results in natural units. When possible, we calculated and reported median effect size (odds ratio $(\mathrm{OR})$, interquartile ranges (IQR)). Due to high heterogeneity across studies, meta-analysis was not feasible.

\section{Main results}

We included two RCTs and four CRCTs involving 352 physicians, 48 residents, and 135 allied health practitioners. Overall risk of bias was low as was quality of the evidence. One comparison was supported by three studies and three comparisons were supported by single studies, but outcomes across the three studies were highly heterogeneous. We found no studies to support EHI versus no alternative. Given these factors, it was not possible to determine the relative effectiveness of interventions. All studies reported practitioner use of EHI, two reported on compliance with electronic practice guidelines, and none reported on patient outcomes.

One trial (139 participants) measured guideline adherence for an electronic versus printed guideline, but reported no difference between groups (median OR 0.85, IQR 0.74 to 1.08). One small cross-over trial (10 participants) reported increased use of clinical guidelines when provided with a mobile versus stationary, desktop computer (mean use per shift: intervention group (IG) 3.6, standard deviation (SD) 1.7 vs. control group (CG) 2.0 (SD 1.9), P value $=0.033$ ). One cross-over trial (203 participants) reported that using a customized versus a generic interface had little impact on practitioners' use of EHI (mean difference in adjusted end-of-study rate: 0.77 logins/ month/user, 95\% confidence interval (CI) CI 0.43 to 1.11). Three trials included education or training and reported increased use of EHI by practitioners following training.

\section{Authors' conclusions}

This review provided no evidence that the use of EHI translates into improved clinical practice or patient outcomes, though it does suggest that when practitioners are provided with EHI and education or training, the use of EHI increases. We have defined use as the activity of logging into an EHI resource, but based on our findings use does not automatically translate to the application of EHI in practice. While using EHI may be an important component of evidence-based medicine, alone it is insufficient to improve patient care or clinical practices. For EHI to be applied in patient care, it will be necessary to understand why practitioners' are reluctant to apply EHI when treating people, and to determine the most effective way(s) to reduce this reluctance.

\section{PLAIN LANGUAGE SUMMARY}

\section{Interventions to increase the use of electronic health information by healthcare practitioners}

\section{Background}

There is a lot of healthcare information available to doctors, nurses, physiotherapists, and other healthcare practitioners. Today, most of this information is electronic (online, Internet, computers), and it is easy to assume that if information is available to practitioners, they will use it to ensure good patient care; but this is not always the case.

\section{Review question}

This review asks whether or not practitioners provided with electronic health information (EHI) will use information more often; whether they will provide better patient care; and whether people treated by practitioners' using EHI are better off.

\section{Study characteristics}

We found six studies involving 535 healthcare practitioners. The studies examined strategies encouraging practitioners to use EHI when caring for patients. We measured practitioners' use of EHI by counting the number of times they logged onto it; by measuring whether or not practitioners' followed the guidance provided by EHI; and by improvements experienced by patients. The studies compared the following strategies: EHI versus printed information (one study); EHI on a "mobile" (e.g. laptop computer) versus a stationary, desktop computer (one study); EHI presented with different search interfaces (an interface is what a user sees when accessing an online resource, think of Google versus Yahoo) (one study); and EHI provided with training (three studies).

\section{Key results}

Interventions to increase the use of electronic health information by healthcare practitioners to improve clinical practice and patient 
The results of this review showed that when provided with a combination of EHI and training, practitioners used the information more often. Two studies measured doctors' use of electronic treatment guidelines, but showed that the electronic aspect of the guidelines did not mean that doctors followed the guidelines. This review provided no information on whether more frequent use of EHI translated into improved clinical practice or whether patients were better off when doctors or nurses used health information when treating them.

\section{Quality of the evidence}

All included studies were randomized controlled trials (clinical studies where people are randomly put into one of two or more treatment groups), which are considered high-quality sources of evidence. However, three of the four comparisons that we examined were supported by only one study each and single studies do not typically produce high-quality evidence. Overall, we rate the body of evidence in this review as low quality. 
SUMMARY OF FINDINGS FOR THE MAINCOMPARISON. [Explanation]

\section{Provision of electronic health information versus printed health information}

Population: newly graduated physicians

Settings: primary care health centers

Intervention: electronic guidelines

Comparison: print guidelines

\begin{tabular}{|c|c|c|c|c|c|}
\hline Outcomes & Results & & $\begin{array}{l}\text { Number of } \\
\text { studies }\end{array}$ & Number of sites (number of participants) & Quality of the evidence (GRADE) \\
\hline $\begin{array}{l}\text { Changes to professional be- } \\
\text { havior - clinical practice, e.g. } \\
\text { consultations compliant with } \\
9 \text { guideline recommendations }\end{array}$ & IG $74.8 \%$ to $96.1 \%$ & CG $80.6 \%$ to $95.6 \%$ & 1 & 96 healthcare centers (139) & $\oplus \oplus \bigcirc \bigcirc$ \\
\hline
\end{tabular}

GRADE: GRADE Working Group Grades of Evidence

$\oplus \oplus \oplus \oplus$ High quality: We are confident that the true effect lies close to that of the estimate of effect

$\oplus \oplus \oplus \bigcirc$ Moderate quality: The true effect is likely to be close to the estimate of effect, but there is a possibility that it may be substantially different

$\oplus \oplus \bigcirc \bigcirc$ Low quality: The true effect may be substantially different from the estimate of effect

$\oplus \bigcirc \bigcirc \bigcirc$ Very low quality: Any estimate of effect is very uncertain

CG: control group; IG: intervention group.

Notes:

Downgrade 1: we downgraded the evidence because of a paucity of data; e.g. only one study for the outcome (GRADE Working Group 2014b).

Downgrade 2: we rated the study at high risk of performance bias due to knowledge of the allocated interventions by participants and personnel during the study, e.g. participants knew that electronic and print information were being compared: " Prior to the study, the participating physicians agreed not to use the other version of the guidelines if it was available in the health centre." 


\section{B A C K G R O U N D}

\section{Description of the condition}

In 2004, a discussion paper commissioned by the World Health Organization (WHO) asked if global access to health information could be achieved by 2015 (Godlee 2004). The question was based, at least in part, on the premise that limited or no access to information was the major barrier to knowledge-based health care in developing countries. In 2015, we know that although technology to support access to health (and other) information is proliferating - even in the developing world where, for example, cell phone access is increasing quickly (World Bank 2012), the actual implementation of healthcare evidence in patient care is nowhere near optimal. On the contrary, suboptimal care is an international problem extending well beyond resource-poor settings (Choi 2012; Driscoll 2011; Esscher 2014; Launay 2014; O'Leary 2014; McGlynn 2003); and quality improvement in health care is on the agendas of government departments, policy-making bodies, and not-for-profit organizations worldwide (consider the US Agency for Healthcare Research and Quality (www.ahrq.gov/), WHO Mental Health Gap Action Programme (www.who.int/mental_health/mhgap/en/); Australian Commission on Safety and Quality in Health Care ( www.safetyandquality.gov.au/); and the UK National Health Service (NHS) National Quality Board (http://www.england.nhs.uk/ ourwork/part-rel/nqb/). Research shows that even for those practitioners able to identify and access healthcare information, there is still the question of how to incorporate information into practice at individual practitioner and organizational levels (Ellen 2013; French 2012; Gagnon 2011; Grimshaw 2012; Hannes 2012; Harvey 2013; Holmes 2014; Judd 2004; Lundgren 2013; Maggio 2013).

Despite these issues, there is evidence from longitudinal studies, that practitioners' use of EHI may improve processes of care by, for example, avoiding unnecessary diagnostic tests (Pluye 2013a; Pluye 2013b); and one pilot study suggested that online searching during patient encounters in primary care may increase the use of health information by practitioners (Van Duppen 2007). This review sought to identify high-level evidence (see Types of studies) to assess the effect of EHI on professional practices or patient outcomes.

\section{How the intervention might work}

Providing practitioners with EHI at the point of patient care or in office settings is one way the intervention might work. Education or training sessions about EHI, whether focused on technical aspects (software or hardware) or on the content of the EHI, may encourage its use. Tailoring EHI to the practice environment or clinical specialty may contribute to increased use (Baker 2010).
Educating practitioners in processes of evidence-based medicine (EBM) may encourage uptake of EHI. An audit and feedback process illustrating the impact of EHI on patient outcomes or clinical practices might encourage the use of $\mathrm{EHI}$ in patient care settings (Ivers 2012). The format, design, and interface of EHI, as well as the technology platform used to deliver it, may also influence its use - presumably the easier it is to navigate EHI, the more likely a practitioner will be to use it. Providing practitioners with convenient access to EHI via laptop or tablet computers, or mobile/ cellular phones; or providing access to synthesized EHI instead of lengthy systematic reviews or meta-analyses may encourage the use of EHI when treating patients.

\section{Why it is important to do this review}

Despite the widespread availability of EHI in high-income settings, patient care is frequently suboptimal. There are similar problems in low- to middle-income country (LMIC) settings where, until recently, access to electronic information was not the norm. With the advent of cell phone networks, LMIC settings have had an opportunity to become better connected to all types of electronic information (World Bank 2012). Given that EHI is becoming a global norm, it is important that we discover how to encourage practitioners to use EHI to inform patient care.

\section{O B J E C T I VES}

To assess the effects of interventions aimed at improving or increasing healthcare practitioners' use of electronic health information (EHI) on professional practice and patient outcomes.

\section{METHOD S}

\section{Criteria for considering studies for this review}

\section{Types of studies}

We included randomized controlled trials (RCTs), cluster randomized controlled trials (CRCTs), non-randomized controlled trials (NRCTs), controlled before-and-after (CBA) studies (with contemporaneous data collection and at least two intervention and two control sites), and interrupted time series (ITS) studies (with a defined point in time when the intervention occurred, and at least three data points before and after implementation of the intervention) according to Cochrane Effective Practice and Organisation of Care (EPOC) Group criteria (EPOC 2015a). 


\section{Types of participants}

Practitioners of any type (physicians, nurses, physiotherapists, psychologists, etc.), including residents or trainees, who were involved in patient care.

\section{Types of interventions}

We considered any intervention that aimed to improve or increase the use of EHI by practitioners to inform clinical practice. EHI could be provided with or without educational support (training); it could be provided differentially - on a network or on a single computer, in an office, or at the bedside. EHI could be new to users, or it could be familiar content presented via different user interfaces; it could be provided on different computer hardware ranging from desktop computers to laptops, from tablet computers to mobile phones.

\section{Types of outcome measures}

We considered objective measures of patient outcomes, such as reduced symptoms or improved response to treatment; and healthcare practitioner behavior, either in their use of EHI to inform care, or in their professional practice behaviors, such as adherence to clinical practice guidelines, or changed processes of patient care.

\section{Primary outcomes}

We included any objective or blinded measure of:

- changes to professional behavior - clinical practice;

- changes to professional behavior - use of EHI;

- patient outcomes, such as improved control of symptoms, resolution of complaint, or decreased length of hospital stay.

\section{Search methods for identification of studies}

For this update, we developed a new, sensitive search strategy. Given the changed strategy, we applied no date limits to our searches. We used two methodologic filters, one to identify RCTs (see Box 6.4.d Lefebvre 2011); and one developed by the Cochrane EPOC Group to identify NRCT designs. We searched The Cochrane Database of Systematic Reviews (CDSR) and the Database of Abstracts of Reviews of Effects (DARE) for related systematic reviews, and the databases listed below for primary studies. We conducted searches in August 2012 and November 2013. Search strategies are presented in : Appendix 1; Appendix 2; Appendix 3; Appendix 4; Appendix 5. For future updates of this review, we intend to supplement our search methods by searching: trial registries, grey literature, and databases focusing on LMIC where we may find studies of EHI interventions using cell/mobile phone technology in LMICs (World Bank 2012).

\section{Databases}

- Cochrane Central Register of Controlled Trials (CENTRAL), The Cochrane Library, 2013, Issue 11, Wiley.

- MEDLINE, 1946 to November 2013, In-Process and other non-indexed citations, OvidSP.

- EMBASE, 1947 to November 2013, OvidSP.

- Health Technology Assessment Database, The Cochrane Library, 2013, Issue 11, Wiley.

- NHS Economic Evaluation Database, The Cochrane Library, 2013, Issue 11, Wiley.

- CINAHL (Cumulative Index to Nursing and Allied Health Literature), 1980 to November 2013, EBSCOHost.

- LISA (Library and Information Science Abstracts), 1969 to November 2013, EBSCOHost.

\section{Searching other resources}

We also:

- reviewed reference lists of related systematic and other reviews, or studies;

- contacted authors of relevant or potentially relevant studies to seek clarification or request unpublished results, or both.

See: Appendix 7; Appendix 8 for details.

\section{Data collection and analysis}

\section{Selection of studies}

We downloaded database search results into Reference Manager bibliographic management software and removed duplicates. Given the relatively large number search results (14,359 unique citations) and time constraints, a review author (MF) and one EPOC editor (Sasha Shepperd) and a Managing Editor (Gerd Flodgren) singly conducted initial title/abstract screening, which is an acceptable approach per Cochrane MECIR conduct standard C39 (MECIR). We assessed inter-rater agreement by double-screening selected citations during the initial screening process. After eliminating 14,102 clearly irrelevant citations, we undertook screening in duplicate for the remaining 257 citations. We retrieved the full text of 75 potentially relevant papers and review authors (MF, JM, DS, KH, ML, PP, RG) assessed them against eligibility criteria. We resolved disagreements at any stage by discussion or third-party arbiter. For studies in languages other than English, we sought translation from colleagues.

\section{Data extraction and management}

Two review authors (from MF, RG, KH, PP, JM, and ML) independently extracted data; we resolved disagreements by discussion or by a third party (EPOC Editor). We used the EPOC Data Extraction form (EPOC 2015b). For studies that reported more than 
one effectiveness outcome, we planned to calculate the median effect size and interquartile range (IQR), but we did not encounter this situation. We used the Review Manager software (RevMan 2014) when conducting the review.

\section{Assessment of risk of bias in included studies}

Two review authors (from MF, PP, ML, RG, and JM) independently assessed risk of bias for each study using the EPOC 'Risk of bias' tool, which is part of the EPOC data extraction form (EPOC 2015b). Given changes to the 'Risk of bias' tool since the original publication of this review, we assessed both new and previously included studies. We resolved disagreements through discussion or by a third party. When necessary, we contacted the primary authors of studies to request missing data regarding sequence generation and allocation concealment. We made an overall assessment of the risk of bias (high, moderate, or low risk of bias) for each of the included studies using the approach suggested in Chapter 12 of the Cochrane Handbook for Systematic Reviews of Interventions (Schunemann 2011).

\section{Unit of analysis issues}

We included two cross-over trials where no washout period was described; thus we report data only for the period before the crossover (Bullard 2004; Haynes 2006).

One CRCT clustered by community, but primary outcome data (number of logins) were reported on individual participants within each cluster (Haynes 2006). The authors made this decision based on an analysis of baseline data for the primary outcome measure (number of logins), where they calculated an intracluster correlation coefficient of -0.02 (95\% confidence interval (CI) -0.16 , 0.12 ) and thus determined that the variation between communities was not important. We agree that for this outcome, reporting individual login data versus cumulative logins per cluster is acceptable and does not misrepresent the effect of intervention.

\section{Dealing with missing data}

In cases of missing or inconsistent data, we contacted authors (Appendix 8).

\section{Assessment of heterogeneity}

The six included studies were heterogeneous, both in their interventions and in reporting of results. Thus, we provided a narrative description of heterogeneity in Description of studies.

\section{Assessment of reporting biases}

We applied neither language nor date restrictions during searching or selection of studies. Our search strategy was highly sensitive and was run across six major biomedical databases and one information science database. Our excluded studies list is demonstrative of a body of non-trial literature on healthcare practitioners' use of EHI. We acknowledged that our search could have extended to bibliographic databases focussed on LMIC (e.g. LILACS and Global Health), to grey literature, and trial registries, and we intend to search these sources for an update of this review. Despite what might be considered our focus on traditional literature sources, we believe our search strategy and inclusion criteria were sensitive and that this review represents a reasonable assessment of extant literature on the use of EHI by healthcare practitioners. Thus, we do not consider this review at high risk for reporting bias, that is, we do not believe there is a large body of extant trial literature unacknowledged in this review.

\section{Data synthesis}

When possible, we calculated and reported the median effect size for each study and the median effect size and IQR across studies. As the heterogeneity of reporting, outcomes, and comparisons precluded meta-analysis, we provided a narrative summary of the results in the text and reported the results for the main outcomes in four 'Summary of findings' tables (Summary of findings for the main comparison; Summary of findings 2; Summary of findings 3; Summary of findings 4).

\section{Subgroup analysis and investigation of heterogeneity}

The search identified too few studies for inclusion to investigate heterogeneity or undertake subgroup analysis.

\section{Sensitivity analysis}

We identified too few studies to perform a sensitivity analysis. In future, should we identify a sufficient number studies with homogenous outcomes, we will consider undertaking this analysis.

\section{Summary of findings}

We presented data on four comparisons in Summary of findings for the main comparison; Summary of findings 2; Summary of findings 3; and Summary of findings 4; and present outcome data on clinical behaviours reported in two studies (Gulmezoglu 2007; Jousimaa 2002) in Table 1. The 'Summary of findings' tables indicate the quality of evidence for each comparison based on GRADE as recommended in the Cochrane Handbook for Systematic Reviews of Interventions (Schunemann 2011). The GRADE approach aids in determining the extent to which readers can be confident in estimates of effect reported in a study, and is based on consideration of multiple factors: within-study risk of bias (methodologic quality), directness of evidence, heterogeneity, precision of effect estimates, and risk of publication bias. Our cumulative assessment of the quality of evidence presented for outcomes in this review was low. 


\section{RE S U L T S}

\section{Description of studies}

See Characteristics of included studies table.

\section{Results of the search}

We identified 23,856 citations of which 9497 were duplicates. We screened 14,359 unique citations and excluded 14,284 after reviewing titles and abstracts. We retrieved full-text articles for the remaining 75 citations. We excluded 69 with reasons (see Characteristics of excluded studies table) and included six (see Characteristics of included studies table); and identified one study protocol (see Ongoing studies table).

Of the six studies included in this review (Figure 1), two were newly identified (Cabell 2001; Campbell 2013), two were included in the original review (Gulmezoglu 2007; Jousimaa 2002), and two were previously excluded studies that we re-assessed based on our decision to consider the use of EHI as representative of practitioner behavior (Bullard 2004; Haynes 2006). 
Figure I. 2013 Study flow diagram.

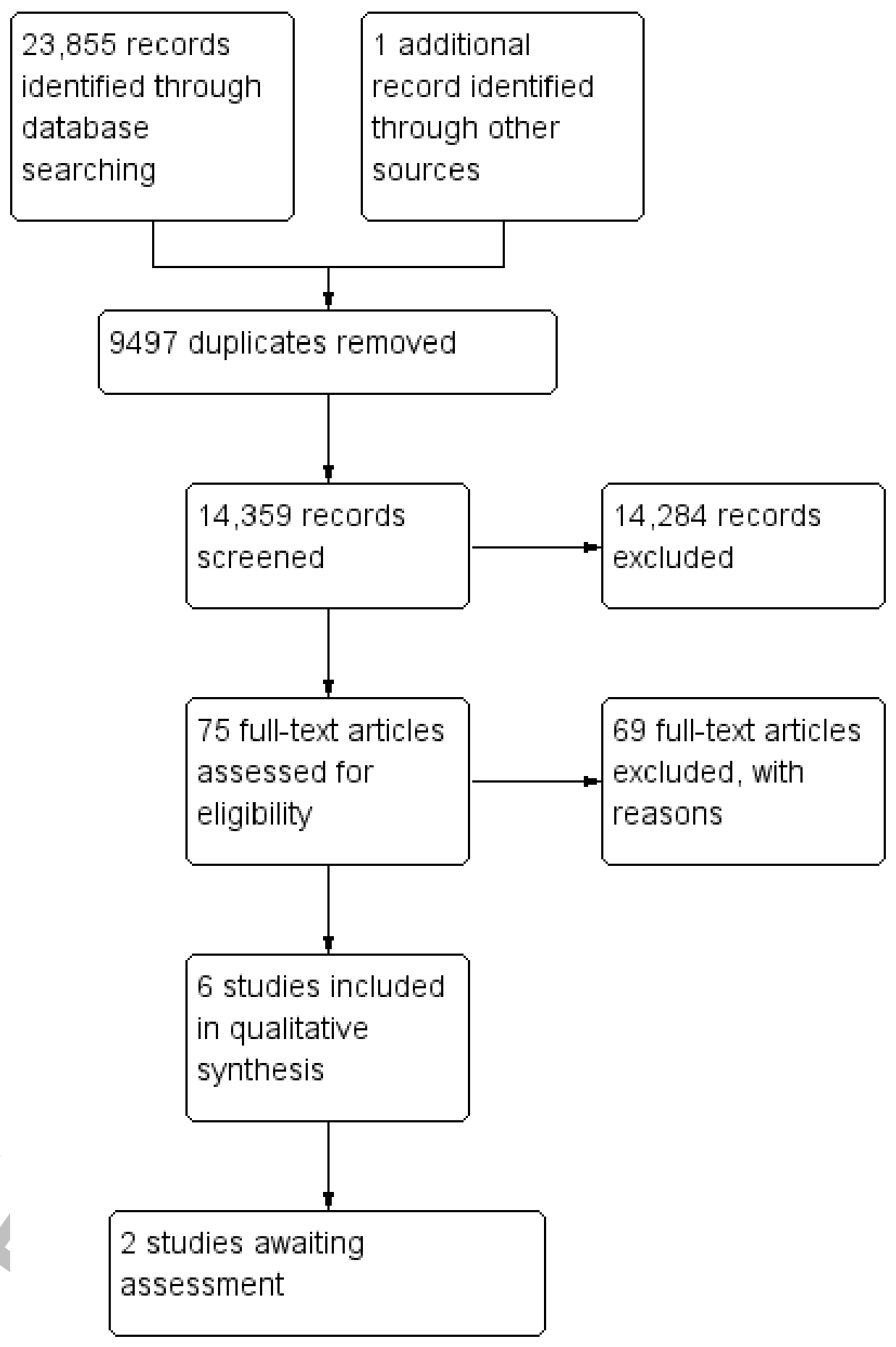




\section{Included studies}

\section{Study design}

We identified two RCTs (Bullard 2004; Cabell 2001), and four CRCTs (Campbell 2013; Gulmezoglu 2007; Haynes 2006; Jousimaa 2002). One RCT (Bullard 2004), and one CRCT (Haynes 1990), were cross-over trials.

\section{Participants}

Five studies included 352 physicians, 48 residents, and 135 allied health practitioners. One study randomized by hospital, so the precise number of physicians and nurses was not available (Gulmezoglu 2007).

Three studies took place in primary care or general internal medicine practices (Cabell 2001; Haynes 2006; Jousimaa 2002), one in obstetrics/gynecology/maternity departments at 40 hospitals (Gulmezoglu 2007), one in an emergency room (Bullard 2004), and one in cerebral palsy health centers (Campbell 2013). Two studies were conducted in Canada (Bullard 2004; Haynes 2006), one in the US (Cabell 2001), one in Australia (Campbell 2013), one in Thailand and Mexico (Gulmezoglu 2007), and one in Finland (Jousimaa 2002).

\section{Type of interventions}

Three studies offered multifaceted, group education (Cabell 2001; Campbell 2013; Gulmezoglu 2007).

Two studies provided audit and feedback (Cabell 2001; Campbell 2013).

One study offered organizational level support (Campbell 2013).

Two studies offered tailored EHI (in terms of subject matter) ( Campbell 2013; Gulmezoglu 2007).

One study offered an enhanced version of EHI via a unique interface (Haynes 2006).

One study offered more convenient access to EHI (e.g. mobile versus stationary, desktop computer) (Bullard 2004).

\section{Comparisons}

\section{Comparison 1: electronic health information versus printed health information}

One trial compared the effects of providing practitioners with an electronic version of evidence-based medicine guidelines (EBMG) versus a printed version (Jousimaa 2002). The duration of the intervention was one month, or 50 patient consultations, whichever occurred first.

\section{Comparison 2: health information via different electronic devices}

One trial compared the effects of providing emergency room physicians with a wireless mobile computer that could be used at the bedside with a stationary, desktop computer located in an office area (Bullard 2004). Both computers provided access to the same clinical practice guidelines. The duration of the study was 10 shifts: five shifts using the mobile computer and five shifts using the desktop computer.

\section{Comparison 3: health information via different user} interfaces

One cross-over trial compared the effects of providing the healthcare practitioners with EHI via usual means compared with an added value user interface and added value EHI content (Haynes 2006). The duration of the intervention was one year.

Comparison 4: electronic health information, with or without an educational or training component, versus no or other education

Three trials provided education or training, or both, in the use of EHI as the core intervention. The duration of the interventions ranged from one, 30-minute instructional session, to three-day workshops.

In one trial, the intervention group received usual and "additional" education (Cabell 2001). Additional education consisted of a onehour didactic session with interactive elements. Usual education consisted of weekly 30-minute sessions with a medical librarian. Both control and intervention residents received support from a Chief Resident during the 12 to 14 overnight shifts worked during the six- to eight-week rotation, but intervention residents were directed to use well-built clinical question (WBCQ) cards to formulate questions arising from patient encounters, to conduct information searches based on these questions, and bring the information back to their teams to inform patient care.

Two trials provided participants with three days of training. One trial offered multifaceted education for two days at the beginning of the intervention period and followed up with a one-day session, eight weeks later (Campbell 2013). The control group received three days of training but the focus was on communication skills. The other trial provided three interactive workshops, one at the beginning of the intervention period; one six weeks later; and one six months later (Gulmezoglu 2007). 
Comparison 5: electronic health information versus no other type or source of information

We identified no studies comparing EHI versus no other type or source of information.

\section{Outcomes}

\section{Changes to professional behavior - clinical practice}

Two studies reported on compliance with clinical practice guidelines: Jousimaa 2002 measured physicians' compliance with a number of guideline recommendations; and Gulmezoglu 2007 looked at changes in 10 recommended clinical practices (see Characteristics of included studies and Table 1 for details).

\section{Changes to professional behavior - use of electronic health information}

Four studies measured frequency of database use: Bullard 2004; Cabell 2001; and Haynes 2006 reported the number of logins to EHI by intervention and control participants; Campbell 2013 reported the number of web page hits for trial participants. One study reported on the mean number of information-seeking consultations over the intervention period (Jousimaa 2002).

\section{Patient outcomes}

No study reported patient outcomes or adverse events.

\section{Excluded studies}

See Characteristics of excluded studies and PRISMA diagram ( Figure 1).

Of the 69 excluded studies, two had no reportable data (Erickson 1998; Wyatt 1998); four had no objective outcome measure (Alper 2005; D’Alessandro 2004; Doran 2010; Malone 2012); six had out-of-scope intervention(s) (Dykes 2005; Elhadad 2005; Gardois 2011; May 2006; Stewart 2005; Kaushal 2010); five had inappropriate participants, i.e. students with no patient care responsibilities (Bhavnani 2006; Di Noia 2003; Forsetlund 2003; Gruppen 2005; Ku 2007); seven had out-of-scope outcomes (in most cases this was knowledge acquisition) (Butzlaff 2004; Casebeer 2003; Grad 2005; Kolner 1986; Kronick 2003; Lapidus 2009; Southard 2003); and the remaining 30 were of inappropriate (Types of studies) design (Allan 2012; Bowden 2000; Coiera 2006; Crouse 2005; Deurenberg 2008; Estabrooks 2003; Freeth 2001; Garg 2003; Goldstein 2002; Gulmezoglu 1997; Hauser 2007; Haynes 1990; Helwig 1998; Horng 2012; Howe 2001; Huber 2000; Ketikidis 2012; Kibbe 2000; King 2007; Kirsch 2004; Langdorf 1995; Lindberg 1997; Miller 2005; Mokhtar 2012; Noone 1998; Ozbolt 1993; Rudin 1996; Rudin 1997; Sackett 1998; Sintchenko 2004).

\section{Risk of bias in included studies}

See 'Risk of bias' within the Characteristics of included studies table, and Figure 2 and Figure 3. We judged the overall risk of bias for the included studies as low.

Figure 2.

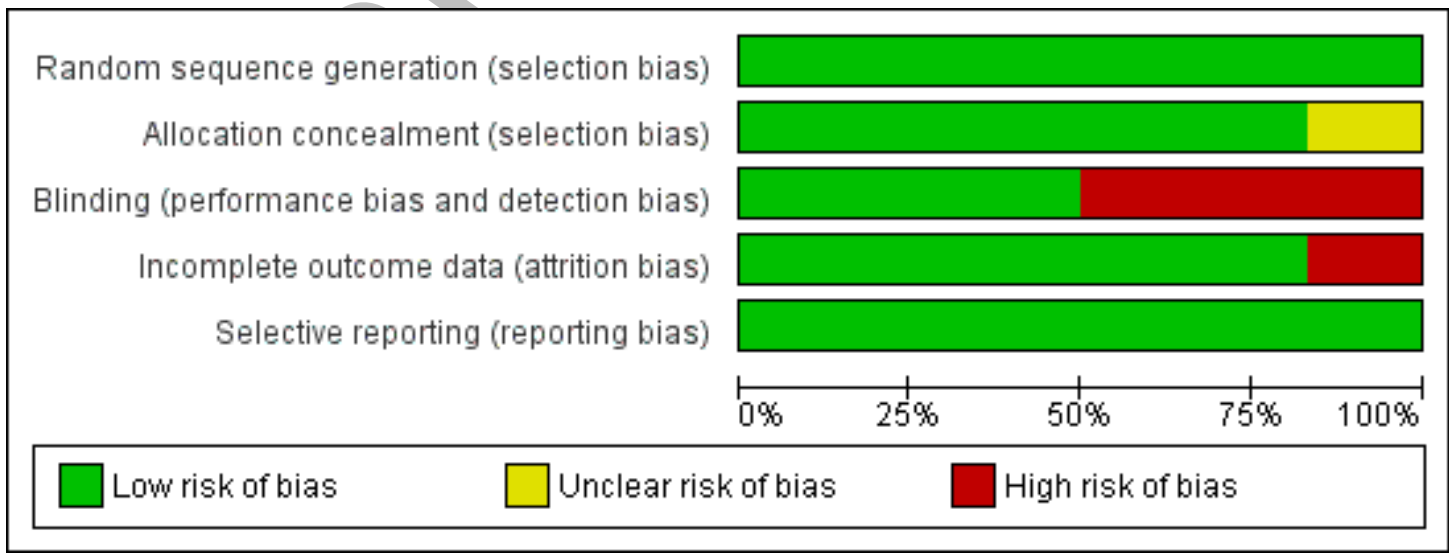

Interventions to increase the use of electronic health information by healthcare practitioners to improve clinical practice and patient 
Figure 3.

\begin{tabular}{|c|c|c|c|c|c|}
\hline & 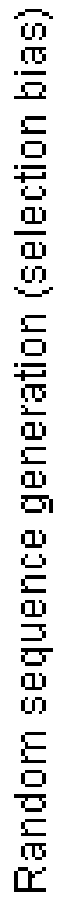 & 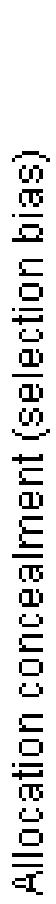 & 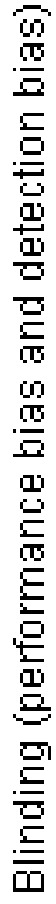 & 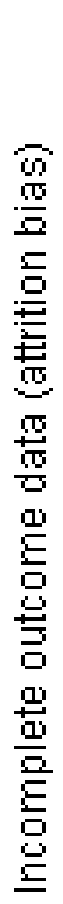 & 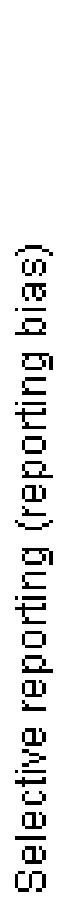 \\
\hline \multicolumn{6}{|l|}{ Bullard 2004} \\
\hline \multicolumn{6}{|l|}{ Cabell 2001} \\
\hline \multicolumn{6}{|l|}{ Campbell 2013} \\
\hline \multicolumn{6}{|l|}{ Gulmezoglu 2007} \\
\hline \multicolumn{6}{|l|}{ Haynes 2006} \\
\hline Jousimaa 2002 & + & $?$ & & & \\
\hline
\end{tabular}

Interventions to increase the use of electronic health information by healthcare practitioners to improve clinical practice and patient 


\section{Allocation}

Five studies reported adequate allocation concealment (Bullard 2004; Cabell 2001; Campbell 2013; Gulmezoglu 2007; Haynes 2006 ), but one did not describe its allocation concealment process and so we rated it at unclear risk of bias (Jousimaa 2002).

\section{Blinding}

Three studies were at low risk (Cabell 2001; Campbell 2013; Gulmezoglu 2007); three were at high risk (Bullard 2004; Jousimaa 2002; Haynes 2006).

In Bullard 2004, participants were not blinded, and evaluators compiled EHI usage data only from those participants using a mobile computer. Thus, we considered the study at high risk for both performance and detection bias.

In Jousimaa 2002, the investigators evaluating the processes of patient care were blinded to participants' allocation and as such, the study was at low risk of detection bias. However, participants were aware of the intervention they received. For this study, we believe the high risk of performance bias outweighed the benefit of low risk detection bias and the overall rating for this aspect of bias was high.

In Haynes 2006, the investigators acknowledged that it was not possible to blind participants; thus, we considered the study at high risk for performance bias. All trial administrators/investigators, except the data analyst, were described as blinded to the participants' allocation; given the role of the data analyst, we considered the risk of detection bias was high.

\section{Incomplete outcome data}

Five studies were at low risk of attrition bias (Bullard 2004; Cabell 2001; Campbell 2013; Haynes 2006; Jousimaa 2002); one was at high risk (Gulmezoglu 2007).

In Gulmezoglu 2007, the main outcome measures (e.g. changes to selected clinical practices), were measured for both control and intervention groups in all hospitals. However, data on process outcomes, including use of EHI, were lost for the Thai control group. Further, it was unclear how many of the intervention participants attended the educational intervention. Given these factors, we rated this study as having a high risk of attrition bias.

\section{Selective reporting}

We assessed all six studies as low risk for reporting bias.

\section{Other potential sources of bias}

Two cross-over studies appeared to be at risk for carry-over effects (Bullard 2004; Haynes 2006).
In Bullard 2004, participants were allocated to a stationary, desktop computer or mobile computer on a shift-by-shift basis using concealed block randomization. Although participants were unaware of their allocation to the stationary (desktop) or mobile computer prior to a shift, they were aware during the shift. Given the three-month time frame for the trial, and number of shifts (10) worked during the three-month period, the wash-out period seemed inadequate, and carry-over effects were likely.

In Haynes 2006, no wash-out period was recorded, and results (higher usage of the full-service option) suggested that participants were aware of the differences between the self-service and fullservice options. While only self-service participants were allocated to use the full-service interface, that is, participants went from a generic to a tailored EHI resource, results from this study were likely influenced by carry-over effects.

One study did not take clustering into account in the analysis (Cabell 2001).

\section{Grading of the evidence}

Using GRADE, we rated the quality of the included studies as moderate for one outcome; and low for three outcomes (GRADE Working Group 2014a). This was due, in part, to a paucity of data for three outcomes; that is, for provision of electronic health information versus printed information, provision of electronic health information on different electronic devices, and provision of electronic health information via different interfaces (e.g. full-service versus self-service), we identified only single studies (Summary of findings for the main comparison; Summary of findings 2; Summary of findings 3). Based on our interpretation of GRADE for such situations, we downgraded each of these studies by one level before assessing other aspects of quality (GRADE Working Group 2014b). While the comparison, provision of electronic health information with training/education versus without training/education, was supported by three studies, the interventions and measurements were so diverse that it was difficult to draw a conclusion or inference (Summary of findings 4). These factors, when combined with risk of bias ratings, led us to rate the overall quality of the evidence as low.

\section{Effects of interventions}

See: Summary of findings for the main comparison Comparison 1: provision of electronic health information versus printed health information; Summary of findings 2 Comparison 2: provision of electronic health information on different electronic devices; Summary of findings 3 Comparison 3: provision of electronic health information via different interfaces: full-service versus self-service; Summary of findings 4 Comparison 4: provision 
of electronic health information with training/education versus without training/education

See Summary of findings for the main comparison; Summary of findings 2; Summary of findings 3; Summary of findings 4). See Table 1 for detailed outcomes reported in Gulmezoglu 2007 and Jousimaa 2002.

\section{Comparison 1: electronic health information versus printed health information}

One CRCT, involving 139 newly qualified physicians at 96 primary health centers, measured guideline compliance for nine aspects of care by practitioners using an electronic versus printed guideline (median odds ratio 0.85 ; IQR 0.74 to 1.08 ) (Jousimaa 2002). The trial also showed that a similar proportion of clinically important (e.g. major or serious in nature) non-compliant decisions were made in both groups (intervention group 47.4\% (407/ $859)$; control group $46.3 \%$ (349/753)); and that the mean number of guideline consultations was similar for both electronic and print guideline users (intervention group 19.3 (3 to 50); control group 18.7 (2 to 50) (Jousimaa 2002). The study was conducted for one month or 50 patient consultations, whichever came first.

\section{Comparison 2: health information via different electronic devices}

One cross-over RCT, involving 10 emergency room physicians, showed that providing practitioners with guidelines on a mobile versus stationary, desktop computer increased the number of times physicians' used the guidelines (intervention group 3.6; control group 2.0; logins/shift/person, P value $=0.033)($ Bullard 2004). The study took place over 10 emergency room shifts; five using the mobile computer; five using the stationary computer.

\section{Comparison 3: health information via different user interfaces}

One CRCT incorporated a cross-over of control participants to the intervention group (Haynes 2006). The intervention was designed to provide health care practitioners with two different types of EHI: the intervention interface, full-service EHI, incorporated a tailored, push component (alerts based on participants' self described areas of clinical interest) and the ability to search for critically appraised articles; the control interface, self-service EHI, provided standard, unenhanced EHI such as bibliographic databases, textbooks, and a static guide about EBM. The study involved 203 primary care or internal medicine physicians and took place over 12 months with follow-up at 19 months.

This study showed that providing practitioners with a value-added, tailored EHI resource (full-service interface) versus standard (selfservice interface) increased use by the full-service users: logins rose by 0.77 logins/month/user (95\% CI 0.43 to 1.11 ). The study also measured use of specific databases and reported that during the intervention period, the full-service group accessed Ovid databases less than the self-service group: 11.2 accesses/participant (95\% CI 6.0 to 16.4 , range 0 to 216 ) compared with 17.3 accesses/participant (95\% CI 11.1 to 23.5; range 0 to 209). A similar finding was reported for the Stat!Ref database, which was also accessed less by the full-service group than the self-service group: 5.6 accesses/ participant (95\% CI 3.2 to 7.9 , range 0 to 62 ) compared with 7.2 accesses/participant (95\% CI 4.1 to 10.4 ; range 0 to 91 ).

\section{Comparison 4: electronic health information with or without educational or training component versus no or other education}

Three trials, involving 48 medical residents at one internal medicine service in Mexico and 135 allied health practitioners at multiple community-based cerebral palsy services in Thailand, provided data for EHI with or without educational or training component versus no or other education (Cabell 2001; Campbell 2013; Gulmezoglu 2007). All three trials showed an increased use of EHI following education, but given the homogeneity of duration and timing, content, and pedagogic strategies in each study, we were unable to ascertain which aspect of each educational session influenced study participants.

Duration of the educational interventions varied among trials from one hour (Cabell 2001) to three days (Campbell 2013; Gulmezoglu 2007); and the three-day interventions differed in terms of timing with one study offering two consecutive days of training at the beginning of the intervention period, followed by a third session eight weeks later (Campbell 2013); the other study offered one day of education at three times - at the beginning of the trial, at six weeks, and at six months (Gulmezoglu 2007). The content of the educational sessions varied across studies, though some similarities were found in Campbell 2013 and Gulmezoglu 2007, which both educated intervention participants in the principles of EBM, applying evidence in clinical practice, and the content and use of (e.g. how to search) a specialized electronic resource, a cerebral palsy-focused Wiki (Campbell 2013), and the WHO Reproductive Health Library (RHL) (Gulmezoglu 2007). Aside from this, the content varied as Cabell 2001 focused on building clinical queries to aid MEDLINE searching; Campbell 2013 educated participants in the use of two patient outcome measures that were integrated into the clinical workflow; and Gulmezoglu 2007 educated participants about implementing change in clinical practice. Pedagogically, the interventions varied. Didactic lecture was the sole strategy used in Cabell 2001, while Campbell 2013 and Gulmezoglu 2007 deployed multifaceted, interactive teaching strategies.

Results showed increased use of EHI across all trials: Cabell 2001 showed that a one-hour didactic lecture in addition to usual education resulted in a higher search activity as compared to usual education alone, with the number of median MEDLINE logins/person/ 
week higher for the intervention group (intervention group 4.4 versus control group 2.1); Campbell 2013 showed that a three-day educational intervention in evidence-based practice (EBP) and use of specialized database (Evidence Alert System (EAS)), resulted in three times as many page hits, as compared to the control group, which received other education (intervention group 6123 versus control group 1677); and Gulmezoglu 2007 reported that a threeday interactive workshop on the WHO RHL increased the use of the RHL over the course of one month for both intervention and control groups, with the intervention group showing a more substantial increase (intervention group from $4.8 \%$ to $34.9 \%$; control group from $7.2 \%$ to $12.7 \%$ ).

Follow-up periods varied by study: Cabell 2001 and Gulmezoglu 2007 had no follow-up and Campbell 2013 had follow-up at eight weeks post intervention, thus we were unable to determine if intervention effects persisted over time for any of the studies.

Comparison 5: electronic health information versus no other type or source of information

We identified no studies comparing EHI versus no other type or source of information. 
ADDITIONAL SUMMARY OF FINDINGS [Explanation]

Provision of electronic health information on different electronic devices

Population: physicians

Settings: hospital emergency room

Intervention: mobile computer

Comparison: desktop computer

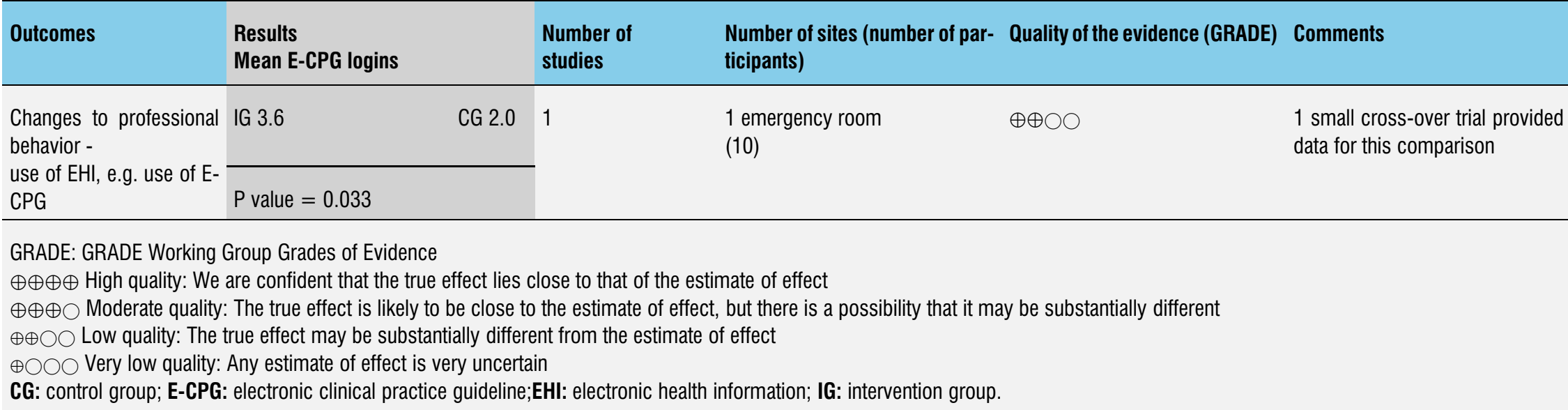

Downgrade 1: we downgraded the evidence because of a paucity of data; e.g. only 1 study for the outcome (GRADE Working Group 2014b).

Downgrade 2: we rated the study at high risk of performance bias due to knowledge of the allocated interventions by participants and personnel during the study, e.g. that desktop vs. mobile

computer use were being compared 
Provision of electronic health information via different interfaces: full-serviceversus self-service

The full-service interface was unique in 2 aspects: 1. included a search engine that returned critically appraised articles rated by physicians; 2 . included push information, e.g. email alerts on topics of interest to the practitioner

Population: physicians

Settings: primary care or internal medicine practices

Intervention: full-service interface

Comparison: usual interface

\begin{tabular}{|c|c|c|c|}
\hline Outcomes & $\begin{array}{l}\text { Results } \\
\text { (mean logins/month/user) }\end{array}$ & $\begin{array}{l}\text { Number of } \\
\text { studies }\end{array}$ & $\begin{array}{l}\text { Number of sites (number of partici- Quality of the evidence (GRADE) } \\
\text { pants) }\end{array}$ \\
\hline \multirow{2}{*}{$\begin{array}{l}\text { Changes to professional be- } \\
\text { havior - } \\
\text { use of EHI }\end{array}$} & CG 2.05 to 1.46 & \multirow[t]{2}{*}{1} & \multirow{2}{*}{$\begin{array}{l}10 \text { communities (clusters), IG } 5 \text { (98); CG } \\
5 \text { (105) }\end{array}$} \\
\hline & $\begin{array}{l}\text { Change in the rate of logins/month/user, } \\
\text { baseline vs. intervention period: } \\
0.77 \text { logins/month/user } \\
\text { ( } 95 \% \mathrm{Cl} 0.43 \text { to } 1.11) \text {, } \\
\text { favoring IG (full-service group) }\end{array}$ & & \\
\hline
\end{tabular}

GRADE: GRADE Working Group Grades of Evidence

$\oplus \oplus \oplus \oplus$ High quality: We are confident that the true effect lies close to that of the estimate of effect

$\oplus \oplus \oplus \bigcirc$ Moderate quality: The true effect is likely to be close to the estimate of effect, but there is a possibility that it may be substantially different

$\oplus \oplus \bigcirc \bigcirc$ Low quality: The true effect may be substantially different from the estimate of effect

$\oplus \bigcirc \bigcirc \bigcirc$ Very low quality: Any estimate of effect is very uncertain

CG: control group; Cl: confidence interval; EHI: electronic health information; IG: intervention group.

We downgraded the evidence because there is only 1 study assessing this comparison 
Provision of electronic health information with training/education versus without training/education

Population: medical residents; allied health personnel; physicians, midwives, nurses

Settings: university hospital; community-based cerebral palsy services; maternity hospitals

Intervention: educational/training sessions on use of EHI resource

Comparison: usual education, no education, or 'other' education

\begin{tabular}{|c|c|c|c|c|c|}
\hline Outcome measure & Results & Number of studies & $\begin{array}{l}\text { Number of sites (number of par- } \\
\text { ticipants) }\end{array}$ & Quality of the evidence (GRADE) & Comments \\
\hline $\begin{array}{l}\text { Changes to professional be- } \\
\text { havior - } \\
\text { use of EHI }\end{array}$ & $\begin{array}{l}3 \text { trials showed that educa- } \\
\text { tion/training in the use of dif- } \\
\text { ferent electronic healthcare re- } \\
\text { sources resulted in increased } \\
\text { use of the resource. All in- } \\
\text { creases were reported differ- } \\
\text { ently and could not be pooled }\end{array}$ & & $\begin{array}{l}\text { Participants: } \\
183 \text { heathcare personnel } \\
\text { (IG 97; CG 86) } \\
40 \text { hospitals } \\
\text { (IG 22, CG 18) } \\
\text { Cerebral palsy clinics across } 4 \\
\text { geographic regions; number of } \\
\text { sites not reported }\end{array}$ & $\oplus \oplus \bigcirc \bigcirc$ & $\begin{array}{l}\text { The data did not permit meta- } \\
\text { analysis }\end{array}$ \\
\hline
\end{tabular}

GRADE: GRADE Working Group Grades of Evidence

$\oplus \oplus \oplus \oplus$ High quality: We are confident that the true effect lies close to that of the estimate of effect

$\oplus \oplus \oplus \bigcirc$ Moderate quality: The true effect is likely to be close to the estimate of effect, but there is a possibility that it may be substantially different

$\oplus \oplus \bigcirc \bigcirc$ Low quality: The true effect may be substantially different from the estimate of effect

$\oplus \bigcirc \bigcirc \bigcirc$ Very low quality: Any estimate of effect is very uncertain

CG: control group; CI: confidence interval; EHI: electronic health information; IG: intervention group.

We downgraded each study by 1 grade due to the heterogeneity of outcomes and interventions - e.g. data could not be pooled in a meaningful manner. We downgraded 1 study an additional grade, due to high attrition bias 


\section{DISCUSSION}

\section{Summary of main results}

This review included two RCTs and four CRCTs (one RCT and one CRCT were cross-over trials) involving 352 physicians, 48 residents, and 135 allied health practitioners. Studies evaluated the effects of interventions aimed at improving practitioners' use of EHI. Studies were heterogeneous in terms of interventions; and even though three studies described an educational intervention, the length and substance of the education in each was sufficiently different to prevent a pooling of effects or report of relative effectiveness. While we assessed risk of bias as low for the studies collectively, our assessment of quality is also low due to the heterogeneity, because of the small size of the studies (three studies had fewer than 50 participants), and because three of four comparisons considered in this review were supported by only one study.

Five studies reported increased use (measured by logins) of EHI and, while this is a positive finding, it is unclear in 4 of the studies which aspect of the interventions influenced participants' behavior. However, one study reported that users of an enhanced or tailored EHI resource used that resource more frequently, and standard bibliographic databases less frequently. This finding provides some indication that the nature of EHI, in this case critically appraised and clinically targetted EHI, may be more useful to practitioners than standard bibliographic databases.

Two studies reported no marked improvement in the use of evidence-based recommendations (health information) in clinical practice, either from an educational intervention (Gulmezoglu 2007), or from providing guidelines in an electronic versus printed format (Jousimaa 2002).

No study reported adverse effects.

\section{Overall completeness and applicability of evidence}

This review sought to identify all relevant studies by using a highly sensitive search strategy and screening a large body of results. Despite this approach, we identified few studies for inclusion. Of the included studies, only one provides some indication of which part of the intervention worked; the remaining five did not provide clear or direct evidence regarding which aspect(s) of the intervention strategies influenced practitioner behavior. Neither do these studies provide evidence regarding the use of EHI on patient outcomes. Consequently, we cannot describe this evidence base as complete or generalizable.

\section{Quality of the evidence}

Although all evidence included in this review was from RCTs, three outcomes were supported by only one study each. Since single studies do not provide sufficient data to determine the relative effectiveness of interventions, we automatically downgraded each study one level on the GRADE scale. Although one comparison, education in addition to EHI, was supported by three studies, the details of the interventions were heterogeneous and we were unable to determine an effect size. Three studies were quite small in that they had fewer than 50 participants; thus, size mitigates against our confidence in the reported findings. We assessed quality based on the risk of bias for each study; while risk of bias was overall low, we found the small sample sizes, heterogeneous outcomes, small number of studies, and paucity of data prevented us from having confidence in the reported effects.

\section{Potential biases in the review process}

We sought to avoid bias by writing and using a highly sensitive search strategy, by applying neither date nor language restrictions, and by searching for study designs other than RCTs. We also implemented dual screening and data extraction. However, we did not search trial registries, grey literature, or databases focused on LMIC. Thus, despite the sensitive strategy, our evidence base may not be comprehensive.

\section{Agreements and disagreements with other studies or reviews}

Two longitudinal studies suggested that practitioners' use of EHI may improve processes of care (Pluye 2013a; Pluye 2013b); and one pilot study suggested that online searching during patient encounters in primary care may increase the use of health information by practitioners (Van Duppen 2007).

\section{A U THORS' CONCLUSIONS}

\section{Implications for practice}

This review provided no evidence that the use of electronic health information (EHI) translates into improved clinical practice or patient outcomes. The studies included in this review provided some evidence that when practitioners were provided with EHI and education in the use of the information, they logged in or used the resource more frequently, or both; however, 'use' did not necessarily translate to compliance with recommended practices, as illustrated in Gulmezoglu 2007 and Jousimaa 2002. One study (Haynes 2006) suggests that EHI which is tailored for practitioners and which provided critically appraised EHI may be more attractive to practitioners than bibliographic databases alone, but there is no evidence that use of the enhanced, tailored EHI improved clinical practice or patient outcomes. In order for EHI to 
be applied to patient care, it will be necessary to understand what factors facilitate use of EHI in clinical practice and which barriers mitigate against its use; and then develop plans to address barriers and increase facilitators.

\section{Implications for research}

Electronic information is a norm in high-income settings, and is becoming more common in low- to middle-income countries (LMIC) where rapidly expanding cell phone networks may provide more opportunity than broadband Internet access - cell phones needing less infrastructure than broadband Internet - to disseminate health information. However, given that the availability of electronic information in resource-rich settings has not led to consistent or widespread improvements in patient care or uptake of evidence into practice (Description of the condition), it cannot be assumed that the provision of EHI alone in LMIC will change healthcare practices. Thus, subsequent studies might focus less on whether or not information is 'electronic' and more on issues of usability, clinical applicability, and mode of delivery (cell/mobile phone or tablet, laptop or other computer). It would be useful if both usability and clinical applicability were determined collaboratively by stakeholders such as healthcare practitioners, technologists (web designers, database managers, etc.), evidence producers, and knowledge translators. The goal of using health information must be to support evidence-based clinical practice and improve patient care, but how to do this is not yet entirely clear. Given that suboptimal care occurs even though evidence is available, any in- tervention to increase the application of health information during patient care must be informed by the best evidence on changing the behavior (professional practices) of healthcare professionals.

While the use of health information should continue to be measured in trials studying the effect of health information on care, it is vital that future studies incorporate measurable patient and clinical practice outcomes. Without patient outcome data, the impetus for using health information may not be clear to practitioners. Future studies might also focus on interventions to increase the use of evidence-based, synthesized EHI resources (Banzi 2010; Prorok 2012; Haynes 2006) versus bibliographic databases such as PubMed. Healthcare organizations using electronic health record systems may provide ideal environments for implementing EHI at the point of care, and measuring the impact of EHI on patient outcomes. It is recommended that organizations with such systems look for multidisciplinary research partners to develop trial protocols.

\section{ACKNOWLEDGEMENTS}

We wish to thank Sasha Shepperd and Gerd Flodgren for initial title and abstract screening of a large data set; and to Gerd Flodgren for methodologic, editorial, and statistical contributions. We sincerely appreciate the excellent copy editing performed by Anne Lawson of the Cochrane Editorial Unit.

\section{REFER E NCES}

\section{References to studies included in this review \\ Bullard 2004 \{published data only\} \\ Bullard MJ, Meurer DP, Colman I, Holroyd BR, Rowe BH. Supporting clinical practice at the bedside using wireless technology. Academic Emergency Medicine 2004;11(11): 1186-92. [PUBMED: 15528583] \\ Cabell 2001 \{published data only\} \\ Cabell CH, Schardt C, Sanders L, Corey GR, Keitz SA. Resident utilization of information technology. Journal of General Internal Medicine 2001;16(12):838-44. \\ Campbell 2013 \{published data only\} \\ Campbell L, Novak I, McIntyre S, Dickson A. Patterns and rates of use of an evidence-based practice intranet resource for allied health professionals: a randomised controlled trial. 5th Biennial Conference of the Australasian Academy of Cerebral Palsy and Developmental Medicine; 2010 Mar 3- 6; Christchurch, New Zealand. 2010. \\ * Campbell L, Novak I, McIntyre S, Lord S. A KT intervention including the evidence alert system to improve clinician's evidence-based practice behavior - a cluster randomized controlled trial. Implementation Science 2013; 8:132. [PUBMED: 24220660]}

Gulmezoglu 2007 \{published data only\}

* Gulmezoglu AM, Langer A, Piaggio G, Lumbiganon P, Villar J, Grimshaw J. Cluster randomised trial of an active, multifaceted educational intervention based on the WHO Reproductive Health Library to improve obstetric practices. BJOG 2007;114(1):16-23. [PUBMED: 17010115] Gulmezoglu AM, Villar J, Grimshaw J, Piaggio G, Lumbiganon P, Langer A. Cluster randomized trial of an active, multifaceted information dissemination intervention based on the WHO Reproductive Health Library to change obstetric practices: methods and design issues [ISRCTN14055385]. BMC Medical Research Methodology 2004;4(1):2.

Gulmezoglu M. A randomised controlled trial to evaluate a programme promoting evidence-based medicine based on the World Health Organization (WHO) Reproductive Health Library, 2007. www.isrctn.com/ISRCTN14055385 (accessed 5 March 2015).

Haynes 2006 \{published data only\}

Haynes RB, Holland J, Cotoi C, McKinlay RJ, Wilczynski NL, Walters LA, et al. McMaster PLUS: a cluster randomized clinical trial of an intervention to accelerate clinical use of evidence-based information from digital 
libraries. Journal of the American Medical Informatics Association 2006;13(6):593-600. [PUBMED: 16929034]

Jousimaa 2002 \{published data only\}

Jousimaa J, Makela M, Kunnamo I, MacLennan G, Grimshaw JM. Primary care guidelines on consultation practices: the effectiveness of computerized versus paperbased versions. A cluster randomized controlled trial among newly qualified primary care physicians. International Journal of Technology Assessment in Health Care 2002;18(3): 586-96. [PUBMED: 12391951]

\section{References to studies excluded from this review}

Allan 2012 \{published data only\}

Allan GM, Ma V, Aaron S, Vandermeer B, Manca D, Korownyk C. Residents' clinical questions: how are they answered and are the answers helpful?. Canadian Family Physician 2012;58(6):e344-51. [PUBMED: 22700742]

Alper 2005 \{published data only\}

Alper BS, White DS, Ge B. Physicians answer more clinical questions and change clinical decisions more often with synthesized evidence: a randomized trial in primary care. Annals of Family Medicine 2005;3(6):507-13. [PUBMED: 16338914]

Bhavnani 2006 \{published data only\} Bhavnani SK, Bichakjian CK, Johnson TM, Little RJ, Peck FA, Schwartz JL, et al. Strategy hubs: domain portals to help find comprehensive information. Journal of the American Society for Information Science and Technology 2006;57(1):4-24.

Bowden 2000 \{published data only\}

* Bowden VR, Greenberg CS, Donaldson NE. Developmental care of the newborn. Online Journal of Clinical Innovations 2000;3(7):1-77. [: CINAHL 2001029526]

Butzlaff 2004 \{published data only\} Butzlaff M, Vollmar HC, Floer B, Koneczny N, Isfort J, Lange $S$. Learning with computerized guidelines in general practice: a randomized controlled trial. Family Practice 2004;21(2):183-8. [PUBMED: 15020389]

Casebeer 2003 \{published data only\} Allison JJ, Kiefe CI, Wall T, Casebeer L, Ray MN, Spettell $\mathrm{CM}$, et al. Multicomponent Internet continuing medical education to promote chlamydia screening. American Journal of Preventive Medicine 2005;28(3):285-90. [PUBMED: 15766617]

* Casebeer LL, Strasser SM, Spettell CM, Wall TC, Weissman N, Ray MN, et al. Designing tailored web-based instruction to improve practicing physicians' preventive practices. Journal of Medical Internet Research 2003;5(3): e20. [PUBMED: 14517111]

Coiera 2006 \{published data only\}

* Coiera E, Magrabi F, Westbrook JI, Kidd MR, Day RO. Protocol for the Quick Clinical study: a randomised controlled trial to assess the impact of an online evidence retrieval system on decision-making in general practice.
BMC Medical Informatics and Decision Making 2006;6:33. [PUBMED: 16928282]

Magrabi F, Westbrook JI, Kidd MR, Day RO, Coiera E. Long-term patterns of online evidence retrieval use in general practice: a 12-month study. Journal of Medical Internet Research 2008;10(1):e6. [PUBMED: 18353750]

Crouse 2005 \{published data only\}

Crouse S. Mobile technology at work. Centralizing a mobile platform simplifies and enhances patient care. Healthcare Informatics 2005;22(7):41. [PUBMED: 16104143]

D’Alessandro 2004 \{published data only\}

D'Alessandro DM, Kreiter CD, Peterson MW. An evaluation of information-seeking behaviors of general pediatricians. Pediatrics 2004;113(1 Pt 1):64-9. [PUBMED: 14702450]

Deurenberg 2008 \{published data only\} Deurenberg R, Vlayen J, Guillo S, Oliver TK, Fervers B, Burgers J. Standardization of search methods for guideline development: an international survey of evidencebased guideline development groups. Health Information and Libraries Journal 2008;25(1):23-30. [PUBMED: 18251909]

Di Noia 2003 \{published data only\} Di Noia J, Schwinn TM, Dastur ZA, Schinke SP. The relative efficacy of pamphlets, $\mathrm{CD}-\mathrm{ROM}$, and the Internet for disseminating adolescent drug abuse prevention programs: an exploratory study. Preventive Medicine 2003; 37(6 Pt 1):646-53. [PUBMED: 14636798]

\section{Doran 2010 \{published data only\}}

Doran DM, Haynes RB, Kushniruk A, Straus S, Grimshaw J, Hall LM, et al. Supporting evidence-based practice for nurses through information technologies. Worldviews on Evidence-Based Nursing 2010;7(1):4-15. [PUBMED: 20028493]

Doran 2013 \{published data only\} Doran DM, Reid-Haughian C, Chilcote A, Bai YQ. A formative evaluation of nurses' use of electronic devices in a home care setting. Canadian Journal of Nursing Research 2013;45(1):54-73. [PUBMED: 23789527]

Dykes 2005 \{published data only\}

Dykes PC, Acevedo K, Boldrighini J, Boucher C, Frumento $\mathrm{K}$, Gray P, et al. Clinical practice guideline adherence before and after implementation of the HEARTFELT (HEART Failure Effectiveness \& Leadership Team) intervention. Journal of Cardiovascular Nursing 2005;20(5):306-14. [PUBMED: 16141775]

Elhadad 2005 \{published data only\} Elhadad N, McKeown K, Kaufman D, Jordan D. Facilitating physicians' access to information via tailored text summarization. AMIA Annual Symposium Proceedings. 2005:226-30. [PUBMED: 16779035]

Erickson 1998 \{published data only\} Erickson S, Warner ER. The impact of an individual tutorial session on MEDLINE use among obstetrics and gynaecology residents in an academic training programme: a randomized trial. Medical Education 1998;32(3):269-73. 
Estabrooks 2003 \{published data only\}

Estabrooks CA, O'Leary KA, Ricker KL, Humphrey

$\mathrm{CK}$. The Internet and access to evidence: how are nurses positioned?. Journal of Advanced Nursing 2003;42(1): 73-81. [PUBMED: 12641814]

Forsetlund 2003 \{published data only\}

Forsetlund L, Bradley P, Forsen L, Nordheim L, Jamtvedt G, Bjorndal A. Randomised controlled trial of a theoretically grounded tailored intervention to diffuse evidence-based public health practice. BMC Medical Education 2003;3:2. [PUBMED: 12694632]

ISRCTN23257060. Towards evidence-based public health. www.isrctn.com/ISRCTN23257060 (assessed 5 March 2015).

Freeth 2001 \{published data only\}

Freeth DS, Weist A, Roberts CM. Provision of an electronic library at the clinical frontline: evaluation of impact on hospital medical staff. Hospital Medicine 2001;62(1):43-5. [PUBMED: 11211462]

\section{Gardois 2011 \{published data only\}}

Gardois P, Calabrese R, Colombi N, Deplano A, Lingua C, Longo F, et al. Effectiveness of bibliographic searches performed by paediatric residents and interns assisted by librarians. A randomised controlled trial. Health Information and Libraries Journal 2011;28(4):273-84. [PUBMED: 22051126]

Garg 2003 \{published data only\}

Garg A, Turtle KM. Effectiveness of training health professionals in literature search skills using electronic health databases - a critical appraisal. Health Information and Libraries Journal 2003;20(1):33-41. [PUBMED: 12641528]

Goldstein 2002 \{published data only\} Goldstein DH, VanDenKerkhof EG, Rimmer MJ. A model for real time information at the patient's side using portable computers on an acute pain service. Canadian Journal of Anaesthesia 2002;49(7):749-54. [PUBMED: 12675060]

Grad 2005 \{published data only\}

Grad RM, Meng Y, Bartlett G, Dawes M, Pluye P, Boillat $\mathrm{M}$, et al. Effect of a PDA-assisted evidence-based medicine course on knowledge of common clinical problems. Family Medicine 2005;37(10):734-40. [PUBMED: 16273453]

Gruppen 2005 \{published data only\}

Gruppen LD, Rana GK, Arndt TS. A controlled comparison study of the efficacy of training medical students in evidence-based medicine literature searching skills. Academic Medicine 2005;80(10):940-4. [PUBMED: 16186614]

Gulmezoglu 1997 \{published data only\} Gulmezoglu AM, Villar J. Providing access to evidencebased information in reproductive health: the WHO Reproductive Health Library for developing countries. Sao Paulo Medical Journal 1997; Vol. 115, issue 4:1469-70. [PUBMED: 9595810]
Hauser 2007 \{published data only\}

Hauser SE, Demner-Fushman D, Jacobs JL, Humphrey SM, Ford G, Thoma GR. Using wireless handheld computers to seek information at the point of care: an evaluation by clinicians. Journal of the American Medical Informatics Association 2007;14(6):807-15. [PUBMED: 17712085]

Haynes 1990 \{published data only\} Haynes RB, McKibbon KA, Walker CJ, Ryan N, Fitzgerald D, Ramsden MF. Online access to MEDLINE in clinical settings. A study of use and usefulness. Annals of Internal Medicine 1990;112(1):78-84. [PUBMED: 2403476]

Helwig 1998 \{published data only\} Helwig AL, Flynn C. Using palm-top computers to improve students' evidence-based decision making. Academic Medicine 1998;73(5):603-4. [PUBMED: 9643923]

Horng 2012 \{published data only\} Horng S, Goss FR, Chen RS, Nathanson LA. Prospective pilot study of a tablet computer in an emergency department. International Journal of Medical Informatics 2012;81(5):314-9. [PUBMED: 22226927]

Howe 2001 \{published data only\} Howe CD. Undergraduate information literacy instruction is not enough to prepare junior doctors for evidence based practice. Evidence Based Library \& Information Practice 2001;7(2):76-8. [: LISA Accession Number: 77478798]

Huber 2000 \{published data only\}

Huber JT, Huggins DW. Assessing electronic information access and use in long-term care facilities in north Texas. Bulletin of the Medical Library Association 2000;88(2): 187-9. [PUBMED: 10783975]

Johnston 2004 \{published data only\} Johnston JM, Leung GM, Tin KY, Ho LM, Lam W, Fielding R. Evaluation of a handheld clinical decision support tool for evidence-based learning and practice in medical undergraduates. Medical Education 2004;38(6): 628-37. [PUBMED: 15189259]

Kaushal 2010 \{published data only\} Kaushal R, Kern LM, Barron Y, Quaresimo J, Abramson EL. Electronic prescribing improves medication safety in community-based office practices. Journal of General Internal Medicine 2010;25(6):530-6. [PUBMED: 20186499]

\section{Ketikidis 2012 \{published data only\}}

Ketikidis P, Dimitrovski T, Lazuras L, Bath PA. Acceptance of health information technology in health professionals: an application of the revised technology acceptance model. Health Informatics Journal 2012;18(2):124-34. [PUBMED: 22733680]

Kibbe 2000 \{published data only\} Kibbe DC. How to search for and find useful health care information on-line. The Case Manager 2000;11(6):32-4. [PUBMED: 11935835]

King 2007 \{published data only\}

King WJ, Le Saux N, Sampson M, Gaboury I, Norris M, Moher D. Effect of point of care information on inpatient 
management of bronchiolitis. BMC Pediatrics 2007;7:4. [PUBMED: 17250764]

Kirsch 2004 \{published data only\}

Kirsch HE. The utility of a federated web-based information management system in an epilepsy center. Neuroinformatics 2004;2(1):119-21. [PUBMED: 15067171]

\section{Kolner 1986 \{published data only\}}

Kolner SJ, Dalrymple PW, Christiansen R. Teaching skills in medical information retrieval to medical students. Journal of Medical Education 1986;61(11):906-10. [PUBMED: 3534269]

Kronick 2003 \{published data only\} Kronick J, Blake C, Munoz E, Heilbrunn L, Dunikowski L, Milne WK. Improving on-line skills and knowledge. A randomized trial of teaching rural physicians to use on-line medical information. Canadian Family Physician 2003;49: 312-7. [PUBMED: 12675544]

Ku 2007 \{published data only\}

Ku YL, Sheu S, Kuo SM. Efficacy of integrating information literacy education into a women's health course on information literacy for RN-BSN students. Journal of Nursing Research 2007;15(1):67-77. [PUBMED: 17370234]

Langdorf 1995 \{published data only\} Langdorf MI, Koenig KL, Brault A, Bradman S, Bearie BJ. Computerized literature search in the ED: patient care impact. Academic Emergency Medicine 1995; Vol. 2, issue 2:157-9. [PUBMED: 7621226]

Lapidus 2009 \{published data only\} Lapidus M, Kostka-Rokosz MD, Dvorkin-Camiel L. Librarian-lead tutorial for enhancement of pharmacy students' information-searching skills in advanced experiential rotations. Medical reference services quarterly 2009;28(4):351-62. [PUBMED: 20183034]

Leung 2003 \{published data only\} Leung GM, Johnston JM, Tin KY, Wong IO, Ho LM, Lam WW, et al. Randomised controlled trial of clinical decision support tools to improve learning of evidence based medicine in medical students. BMJ (Clinical Research ed.) 2003;327(7423):1090. [PUBMED: 14604933]

Lindberg 1997 \{published data only\} Lindberg DA, Humphreys BL. Medical informatics. JAMA 1997;277(23):1870-2. [PUBMED: 9185808]

Malone 2012 \{published data only\} Malone DC, Saverno KR. Evaluation of a wireless handheld medication management device in the prevention of drugdrug interactions in a Medicaid population. Journal of Managed Care Pharmacy 2012;18(1):33-45. [PUBMED: 22235953]

May 2006 \{published data only\} May MW, Quattlebaum C, Parsons K. Rx mobile: patient information at the point of care. American Journal of Health-System Pharmacy 2006;63(5):456-60. [PUBMED: 16484520]
Miller 2005 \{published data only\}

Miller J, Shaw-Kokot JR, Arnold MS, Boggin T, Crowell $\mathrm{KE}$, Allegri $\mathrm{F}$, et al. A study of personal digital assistants to enhance undergraduate clinical nursing education. Journal of Nursing Education 2005;44(1):19-26. [PUBMED: 15673170]

\section{Mokhtar 2012 \{published data only\}} Mokhtar IA, Majid S, Foo S, Zhang X, Theng YL, Chang $\mathrm{YK}$, et al. Evidence-based practice and related information literacy skills of nurses in Singapore: an exploratory case study. Health Informatics Journal 2012;18(1):12-25. [PUBMED: 22447874]

\section{Nixon 2000 \{published data only\}} Nixon SJ, Munro MM, Sands I, Dee EG, Smith JA. Is Intranet technology the low cost, quick fix solution for Scotland's clinical information technology chaos? Results of a pilot study. Scottish Medical Journal 2000;45(5):140-3. [PUBMED: 11130296]

Noone 1998 \{published data only\} Noone J, Warren J, Brittain M. Information overload: opportunities and challenges for the GP's desktop. Studies in Health Technology and Informatics 1998;52 Pt 2:1287-91. [PUBMED: 10384667]

Nussbaum 1998 \{published data only\} Nussbaum GM, Ault SP. The best little data warehouse. Journal of Healthcare Information Management 1998;12(4): 79-93. [PUBMED: 10345836]

\section{Oak 2008 \{published data only\}}

Oak K, Gegg R. Increasing the rural general practitioners' use of library and information services through publicity: a randomized controlled trial in Cornwall, UK. Health Information and Libraries Journal 2008;25(3):208-17. [PUBMED: 18796081]

Ogescu 2008 \{published data only\} Ogescu C, Plaisanu C, Udrescu F, Dumitru S. Improving healthcare services using web based platform for management of medical case studies. Studies in Health Technology and Informatics 2008;137:165-71. [PUBMED: 18560078]

Oliveri 2004 \{published data only\} Oliveri RS, Gluud C, Wille-Jorgensen PA. Physicians'skills with evidence-based medicine. Concepts, information retrieval and use [Laegers fortrolighed med evidensbaseret medicin. Begreber, informationssogning og anvendelse]. Ugeskrift for Laeger 2004;166(45):4040-3. [PUBMED: 15565963]

Ozbolt 1993 \{published data only\} Ozbolt JG, Graves JR. Clinical nursing informatics. Developing tools for knowledge workers. Nursing Clinics of North America 1993;28(2):407-25. [PUBMED: 8516182]

Peterson 1983 \{published data only\}

Peterson H. Ten years experience with a regional health information system - the Stockholm County health care information system. Australian Health Review 1983;6(4): 66-70. [PUBMED: 10264940] 
Rudin 1996 \{published data only\}

Rudin JL. Combined internal medicine and pharmaceutical electronic reference resources: part 1. Compendium of Continuing Education in Dentistry 1996;17(9):822-5; 82830. [PUBMED: 9161155]

Rudin 1997 \{published data only\}

Rudin JL. Combined internal medicine and pharmaceutical electronic reference resources: part 2. Compendium of Continuing Education in Dentistry 1997;18(1):28-30; 32-4; 36-8. [PUBMED: 9161135]

Sackett 1998 \{published data only\}

Sackett DL, Straus SE. Finding and applying evidence during clinical rounds: the "evidence cart". JAMA 1998; 280(15):1336-8. [PUBMED: 9794314]

Safran 1993 \{published data only\}

Safran C, Rind DM, Davis RM, Currier J, Ives D, Sands DZ, et al. An electronic medical record that helps care for patients with HIV infection. Proceedings/the ... Annual Symposium on Computer Application [sic] in Medical Care. Symposium on Computer Applications in Medical Care. 1993:224-8. [PUBMED: 8130466]

Sanchez-Mendiola 2012 \{published data only\} Sanchez-Mendiola M, Kieffer-Escobar LF, Marin-Beltran S, Downing SM, Schwartz A. Teaching of evidence-based medicine to medical students in Mexico: a randomized controlled trial. BMC Medical Education 2012;12:107. [PUBMED: 23131115]

Shabi 2011 \{published data only\} Shabi IN, Shabi OM, Akewukereke MA, Udofia EP. Physicians utilisation of internet medical databases at the tertiary health institutions in Osun State, south west, Nigeria. Health ilnformation and Libraries Journal 2011;28 (4):313-20. [PUBMED: 22051130]

Sintchenko 2004 \{published data only\} Sintchenko V, Coiera E, IredellJR, Gilbert GL. Comparative impact of guidelines, clinical data, and decision support on prescribing decisions: an interactive web experiment with simulated cases. Journal of the American Medical Informatics Association 2004;11(1):71-7. [PUBMED: 14527970]

Southard 2003 \{published data only\} Southard BH, Southard DR, Nuckolls J. Clinical trial of an Internet-based case management system for secondary prevention of heart disease. Journal of Cardiopulmonary Rehabilitation 2003;23(5):341-8. [PUBMED: 14512778]

Stewart 2005 \{published data only\} Stewart M, Marshall JN, Ostbye T, Feightner JW, Brown JB, Harris S, et al. Effectiveness of case-based on-line learning of evidence-based practice guidelines. Family Medicine 2005;37(2):131-8. [PUBMED: 15690254]

Tig 2012 \{published data only\}

Tig EO, Dulger GA, Hidiroglu S, Toklu HZ. The use of electronic information resources by community pharmacists [in Turkish]. Marmara Pharmaceutical Journal 2012;16(1): 29-35. [: EMBASE: 2013579016]
Valentino 1974 \{published data only\}

Valentino HN. Real-time HIS has medical uses. Hospitals 1974;48(22):54-8. [PUBMED: 4435780]

Williams 2013 \{published data only\} Williams K, Hagemann TM, Schaeffer S. Use of electronic learning modules for teaching pharmacy and nursing staff: how to locate and utilize drug information sources in a poison control center. Currents in Pharmacy Teaching and Learning 2013;5:39-43.

Wyatt 1998 \{published data only\} Wyatt JC, Paterson-Brown S, Johanson R, Altman DG, Bradburn MJ, Fisk NM. Randomised trial of educational visits to enhance use of systematic reviews in 25 obstetric units. BMJ (Clinical Research Ed.) 1998;317(7165): 1041-6. [PUBMED: 9774287]

\section{References to ongoing studies}

Haynes 2014 \{unpublished data only\}

* Haynes BR, Agoritsas T. Multifaceted online interventions to increase the quantity and quality of searching for current best evidence to answer clinical questions [trial protocol]. clinicaltrials.gov/ct2/show/NCT02038439 2014.

\section{Additional references}

\section{Baker 2010}

Baker R, Camosso-Stefinovic J, Gillies C, Shaw EJ, Cheater F, Flottorp S, et al. Tailored interventions to overcome identified barriers to change: effects on professional practice and health care outcomes. Cochrane Database of Systematic Reviews 2010, Issue 3. [DOI: 10.1002/ 14651858.CD005470.pub2]

Banzi 2010

Banzi R, Liberati A, Moschetti I, Tagliabue L, Moja L. A review of online evidence-based practice point-of-care information summary providers. Journal of Medical Internet Research 2010;12(3):e26. [PUBMED: 20610379]

Choi 2012

Choi JS, Kim CS, Bae EH, Ma SK, Jeong MH, Kim YJ, et al. Suboptimal medical care of patients with ST-elevation myocardial infarction and renal insufficiency: results from the Korea Acute Myocardial Infarction Registry. BMC Nephrology 2012;13:110. [PUBMED: 22966970]

\section{Driscoll 2011}

Driscoll A, Beauchamp A, Lyubomirsky G, Demos L, McNeil J, Tonkin A. Suboptimal management of cardiovascular risk factors in coronary heart disease patients in primary care occurs particularly in women. Internal Medicine Journal 2011;41(10):730-6. [PUBMED: 21627740]

Ellen 2013

Ellen ME, Leon G, Bouchard G, Lavis JN, Ouimet M, Grimshaw JM. What supports do health system organizations have in place to facilitate evidence-informed decision-making? A qualitative study. Implementation Science 2013;8:84. [PUBMED: 23915278] 


\section{EPOC 2015a}

Effective Practice, Organisation of Care (EPOC). What study designs should be included in an EPOC review and what should they be called? EPOC Resources for review authors. Oslo: Norwegian Knowledge Centre for the Health Services; 2015. epoc.cochrane.org/epoc-specificresources-review-authors.

\section{EPOC 2015b}

Effective Practice, Organisation of Care (EPOC). Good practice data extraction form. EPOC Resources for review authors. Oslo: Norwegian Knowledge Centre for the Health Services; 2015. epoc.cochrane.org/epoc-specificresources-review-authors.

\section{Esscher 2014}

Esscher A, Binder-Finnema P, Bodker B, Hogberg U, MulicLutvica A, Essen B. Suboptimal care and maternal mortality among foreign-born women in Sweden: maternal death audit with application of the 'migration three delays' model. BMC Pregnancy and Childbirth 2014;14:141. [PUBMED: 24725307]

\section{French 2012}

French SD, Green SE, O'Connor DA, McKenzie JE, Francis JJ, Michie S, et al. Developing theory-informed behaviour change interventions to implement evidence into practice: a systematic approach using the Theoretical Domains Framework. Implementation Science 2012;7:38. [PUBMED: 22531013]

\section{Gagnon 2011}

Gagnon MP, Labarthe J, Legare F, Ouimet M, Estabrooks $\mathrm{CA}$, Roch $\mathrm{G}$, et al. Measuring organizational readiness for knowledge translation in chronic care. Implementation Science 2011;6:72. [PUBMED: 21752264]

Godlee 2004

Godlee F, Pekenham-Walsh N, Ncayiyana D, Cochen B, Packer A. Can we achieve health information for all by 2015?. Lancet 2004;364(9430):295-300. [PUBMED: 15262109]

GRADE Working Group 2014a

GRADE Working Group. Grading of Recommendations Assessment, Development and Evaluation, 2014. www.gradeworkinggroup.org/intro.htm (accessed June 2013).

GRADE Working Group 2014b GRADE Working Group. Sparse or imprecise data, 2014. www.gradeworkinggroup.org/FAQ/sparse data.htm (accessed January 2015).

Grimshaw 2012

Grimshaw JM, Eccles MP, Lavis JN, Hill SJ, Squires JE. Knowledge translation of research findings. Implementation Science 2012;7:50. [PUBMED: 22651257]

\section{Gülmezoglu 2004}

Gülmezoglu AM, Villar J, Grimshaw J, Piaggio G, Lumbiganon P, Langer A. Cluster randomized trial of an active, multifaceted information dissemination intervention based on the WHO Reproductive Health Library to change obstetric practices: methods and design issues. $B M C$

Medical Research Methodology 2004;4:2.

\section{Hannes 2012}

Hannes K, Goedhuys J, Aertgeerts B. Obstacles to implementing evidence-based practice in Belgium: a context-specific qualitative evidence synthesis including findings from different health care disciplines. Acta Clinica Belgica 2012;67(2):99-107. [PUBMED: 22712165]

\section{Harvey 2013}

Harvey G. The many meanings of evidence: implications for the translational science agenda in healthcare. International Journal of Health Policy and Management 2013;1(3):187-8. [PUBMED: 24596862]

\section{Holmes 2014}

Holmes BJ, Schellenberg M, Schell K, Scarrow G. How funding agencies can support research use in healthcare: an online province-wide survey to determine knowledge translation training needs. Implementation Science 2014;9 (1):71. [PUBMED: 24906229]

\section{Ivers 2012}

Ivers N, Jamtvedt G, Flottorp S, Young JM, OdgaardJensen J, French SD, et al. Audit and feedback: effects on professional practice and healthcare outcomes. Cochrane Database of Systematic Reviews 2012, Issue 6. [DOI: 10.1002/14651858.CD000259.pub3]

\section{Judd 2004}

Judd M. Examining the Use of Evidence-Based Resources Among Physiotherapists in Canada [dissertation]. Ottawa, ON: University of Ottawa, 2004.

\section{Launay 2014}

Launay E, Gras-Le Guen C, Martinot A, Assathiany R, Martin E, Blanchais T, et al. Why children with severe bacterial infection die: a population-based study of determinants and consequences of suboptimal care with a special emphasis on methodological issues. PLoS One 2014; 9(9):e107286. [PUBMED: 25247401]

Lefebvre 2011

Lefebvre C, Manheimer E, Glanville J. Chapter 6: Searching for studies. In: Higgins JPT, Green S (editors). Cochrane Handbook for Systematic Reviews of Interventions Version 5.1.0 [updated March 2011]. The Cochrane Collaboration, 2011. Available from www.cochrane-handbook.org.

\section{Lundgren 2013}

Lundgren L, Amodeo M, Chassler D, Krull I, Sullivan L. Organizational readiness for change in communitybased addiction treatment programs and adherence in implementing evidence-based practices: a national study. Journal of Substance Abuse Treatment 2013;45(5):457-65. [PUBMED: 23928378]

\section{Maggio 2013}

Maggio LA, Tannery NH, Chen HC, ten Cate O, O’Brien B. Evidence-based medicine training in undergraduate medical education: a review and critique of the literature published 2006-2011. Academic Medicine 2013;88(7): 1022-8. [PUBMED: 23702528] 


\section{McGlynn 2003}

McGlynn EA, Asch SM, Adams J, Keesey J, Hicks J, DeCristofaro A, et al. The quality of health care delivered to adults in the United States. New England Journal of Medicine 2003;348(26):2635-45. [PUBMED: 12826639]

\section{MECIR}

Chandler J, Churchill R, Higgins J, Lasserson T, Tovey D. Methodological standards for the conduct of new Cochrane Intervention Reviews (version 2.3), 2013. hiv.cochrane.org/sites/hiv.cochrane.org/files/uploads/ MECIR ' conduct 'standards $\% 202 \% 203 \% 2002122013$.pdf (accessed 5 March 2015).

\section{O'Leary 2014}

O’Leary F, McGarvey K, Christoff A, Major J, Lockie F, Chayen G, et al. Identifying incidents of suboptimal care during paediatric emergencies-an observational study utilising in situ and simulation centre scenarios. Resuscitation 2014;85(3):431-6. [PUBMED: 24321323]

\section{Pluye 2013a}

Pluye P, Grad RM, Johnson-Lafleur J, Granikov V, Shulha $M$, Marlow B, et al. Number needed to benefit from information (NNBI): proposal from a mixed methods research study with practicing family physicians. Annals of Family Medicine 2013;11(6):559-67. [PUBMED: 24218380]

\section{Pluye 2013b}

Pluye P, Grad RM, Repchinsky C, Joyaisas B, JohnsonLafleur J, Carrier ME, et al. Four levels of outcome of information seeking: a mixed methods study in primary health care. Journal of the American Society for Information Science and Technology 2013;64(1):108-25.

\section{Prorok 2012}

Prorok JC, Iserman EC, Wilczynski NL, Haynes RB. The quality, breadth, and timeliness of content updating vary substantially for 10 online medical texts: an analytic survey. Journal of Clinical Epidemiology 2012;65(12):1289-95. [PUBMED: 22974495]

\section{RevMan 2014}

The Nordic Cochrane Centre, The Cochrane Collaboration. Review Manager (RevMan). 5.3. Copenhagen: The Nordic Cochrane Centre, The Cochrane Collaboration, 2014.

\section{Schunemann 2011}

Schunemann HJ, Oxman AD, Vist GE, Higgins JPT, Deeks JJ, Glasziou P, et al. Chapter 12: Interpreting results and drawing conclusions. In: Higgins JPT, Green S (editors). Cochrane Handbook for Systematic Reviews of Interventions Version 5.1.0 [updated March 2011]. The Cochrane Collaboration, 2011. Available from www.cochrane-handbook.org. [: www.cochranehandbook.org]

\section{Van Duppen 2007}

Van Duppen D, Aertgeerts B, Hannes K, Neirinckx J,

Seuntiens L, Goossens F, et al. Online on-the-spot searching increases use of evidence during consultations in family practice. Patient Education and Counseling 2007;68(1): 61-5. [PUBMED: 17540531]

\section{World Bank 2012}

World Bank. Mobile phone access reaches three quarters of planet's population [press release], 2012. www.worldbank.org/en/news/press-release/2012/07/ 17/mobile-phone-access-reaches-three-quarters-planetspopulation (accessed 5 March 2015).

* Indicates the major publication for the study 


\section{CHARACTERISTICS OF STUDIES}

\section{Characteristics of included studies [ordered by study ID]}

Bullard 2004

\begin{tabular}{|c|c|}
\hline Methods & $\begin{array}{l}\text { Study design: RCT } \\
\text { Data collection: data collected through automated tracking of database logins } \\
\text { Unit of analysis issues: no }\end{array}$ \\
\hline Participants & $\begin{array}{l}\text { Participants: } 10 \text { full-time physicians ( }>75 \% \text { of study site ER physicians expressed an } \\
\text { interest of being involved in the study) } \\
\text { Total number randomized: each of } 10 \text { volunteer ER physicians was randomized using } \\
\text { a matched-pair design to work } 5 \text { shifts in using standard methods (DC access) and } 5 \\
\text { shifts with a wirelessly networked MC } \\
\text { Practitioners lost to follow-up: } 0 \\
\text { Baseline characteristics of participants: } \\
\text { Age, median (IQR): } 35 \text { years (32-37) } \\
\text { Gender: } 100 \% \text { men } \\
\text { Qualifications: } 6 \text { ( } 60 \% \text { ) had certification in emergency medicine from the College of } \\
\text { Family Physicians of Canada, and } 4 \text { ( } 40 \% \text { ) had specialty (American Board of Emergency } \\
\text { Medicine or Fellow of the Royal College of Physicians of Canada) training ( }>4 \text { years of } \\
\text { program training) } \\
\text { Setting: ER (academic, tertiary-care ER with } 75,000 \text { annual visits); non-critical ER areas } \\
\text { Country: Canada }\end{array}$ \\
\hline
\end{tabular}

Interventions

Description: $\mathrm{MC}$ vs. DC access to electronic CPG and other health information and a 1-to-1 session on use of the MC

Type of intervention:

Organisational: provision of MC access at point of care

Study period: 24 June 2002 to 30 September 2002

Duration of intervention: 5 shifts per physician

Control: 5 shifts with the standard DC

Outcomes

Number of logins to the system (utilization of electronic CPGs and other material available via the electronic system)

Notes

Risk of bias

\begin{tabular}{l|l} 
Bias & Authors' judgement
\end{tabular}

Random sequence generation (selection Low risk bias)

"Each of ten volunteer emergency physicians was randomised using a matched-pair design to work five shifts in standard fashion (desktop computer) and five shifts with a wireless networked (mobile computer)"

Interventions to increase the use of electronic health information by healthcare practitioners to improve clinical practice and patient 27 outcomes (Review)

Copyright $\odot 2015$ The Cochrane Collaboration. Published by John Wiley \& Sons, Ltd. 
Bullard 2004 (Continued)

\begin{tabular}{|c|c|c|}
\hline Allocation concealment (selection bias) & Low risk & $\begin{array}{l}\text { "Concealed, block randomisation was used } \\
\text { to allocate the work mode [mobile or desk- } \\
\text { top computer] for each physician's ten as- } \\
\text { signed shifts" }\end{array}$ \\
\hline $\begin{array}{l}\text { Blinding (performance bias and detection } \\
\text { bias) } \\
\text { All outcomes }\end{array}$ & High risk & $\begin{array}{l}\text { Participants were not blinded to the inter- } \\
\text { vention, DC or MC } \\
\text { Use data for each physician/participant } \\
\text { were compared between shifts (while as- } \\
\text { signed to the MC vs. DC) }\end{array}$ \\
\hline $\begin{array}{l}\text { Incomplete outcome data (attrition bias) } \\
\text { All outcomes }\end{array}$ & Low risk & $\begin{array}{l}\text { Data were collected automatically at each } \\
\text { login (p. } 1188, \operatorname{col} 2 \text {, para } 2)\end{array}$ \\
\hline Selective reporting (reporting bias) & Low risk & $\begin{array}{l}\text { Use of electronic information sources were } \\
\text { tracked automatically by the system. "Uti- } \\
\text { lizations of ...the CPGs.. for each individ- } \\
\text { ual were compared between shifts (while } \\
\text { assigned to the mobile and desktop com- } \\
\text { puters)" (p. 1188, col 2, para 3) }\end{array}$ \\
\hline
\end{tabular}

\section{Cabell 2001}

$\begin{array}{ll}\text { Methods } & \text { Study design: RCT } \\ & \text { Data collection: automated tracking of database logins } \\ & \text { Unit of analysis issues: none noted }\end{array}$

Participants

Participants: 48 medical residents

Total number randomized: 48; 24 in each group

Practitioners lost to follow-up: 1

Baseline characteristics of participants:

Age, median (IQR): IG: 29.0 years (2.9); CG 29.3 years (3.2)

Gender: IG: 24; 8 women; CG: 24; 8 women

Setting: general internal medicine service, Duke University Medical Center

Country: USA

Interventions

\section{Description:}

- 1-hour didactic session taught by principle investigator (Cabell) and a medical librarian: introduction to EBM process; discussion of WBCQ based on PICO framework; introduction to WBCQ cards; practice formulating questions; overview of MEDLINE searching; practice searching MEDLINE (p. 839, Figure 1; p. 839, last para, col 1)

- Using WBCQ cards to "record clinical questions generated from each admission" (p. 839, col 2, para 1; p. 40, Figure 2)

- "Use of WBCQ cards to build searchable questions generated from admissions to the general medicine service. The cards were used each long call night [and were presented to] the chief resident [during one on one sessions]. During these sessions... residents presented [his/her] admissions [and] clinical questions derived from [them]. 
Cabell 2001 (Continued)

[Then the chief resident emphasized] the relationship between the development of a clinical questions, the use of the WBCQ cards, and...expedient searching of the medical literature" (p. 839, col 2, para 2). "Residents kept the [WBCQ] cards and used them to aid in formulating their search strategies in MEDLINE...the residents were encouraged to...search each...question, and to bring the data back to their teams to aid in patient care" (p. 839, col 2, para 3). The IG also received the usual education Type of intervention:

Multifaceted education: didactic session with interactive aspects - MEDLINEsearching and practice formulating clinical questions

Provision of educational material: residents were provided with WBCQ cards to use during on call night shifts

Study period: September 1998 to May 1999

Intervention delivery periods: 6 inpatient medical rotations, each lasting 6-8 weeks(p. 838, col 2, para 4)

Duration of intervention: 1 -hour didactic session (during week 1 of rotation) (p. 839, col 1, para 6). 12-14 meetings with chief resident during long-call nights(p. 839, col 1, para 1)

Data collection time: not clearly stated "The data collected from the first week of each rotation were not used for analysis to reduce contamination between groups at the time of rotation changes" (p. 843, col 2, para 4)

Comparison: CG received "usual" educational sessions with a medical librarian and also met with the chief resident: "the chief resident sessions were similar for each group except for the time spent on practical experience formulating well-built clinical questions and the use of the WBCQ cards" (p. 840, col 1, para 1)

Notes:

Chief resident training:

Chief residents were trained in EBM (p. 839, col 1, para 2). "The chief residents receive specific training in EBM both through our training program and through workshop attendance. The chief residents attend the McMaster University workshop on the principles of teaching EBM. This workshop combines didactic lessons with small group discussion sections. In addition, practice teaching sessions with role playing are used to facilitate the development of practical skills in teaching EBM to learners such as medical residents"

\section{Usual education:}

The IG also received "usual" education with a medical librarian (p. 839, col 1, para 4). Usual education consisted of: "The medical librarian sessions were 30-minute lessons on the different resources available to locate important medical information. These sessions took place just before morning report 1 day per week. These sessions followed a structured curriculum that included the use of medical subject headings and subheadings, text words, EBM filters, and other EHI such as Best Evidence and the Cochrane Database of Systematic Reviews. Each week the medical librarian provided pragmatic examples of how the answers to medical questions could be answered utilizing specific techniques and electronic medical resources [e.g. EHI]" medicine rotation 
Cabell 2001 (Continued)

\section{Risk of bias}

\begin{tabular}{|c|c|c|}
\hline Bias & Authors' judgement & Support for judgement \\
\hline $\begin{array}{l}\text { Random sequence generation (selection } \\
\text { bias) }\end{array}$ & Low risk & $\begin{array}{l}\text { "[48] residents...were randomly assigned in } \\
\text { blocks by coin flip to a teaching interven- } \\
\text { tion or to a control group" (p. } 838, \text { col } 2 \text {, } \\
\text { para 4) }\end{array}$ \\
\hline Allocation concealment (selection bias) & Low risk & $\begin{array}{l}\text { Adequate due to block randomization(p. } \\
838 \text { ) }\end{array}$ \\
\hline $\begin{array}{l}\text { Blinding (performance bias and detection } \\
\text { bias) } \\
\text { All outcomes }\end{array}$ & Low risk & $\begin{array}{l}\text { Performance bias: low } \\
\text { "Although study participants were blinded to } \\
\text { the study question, it is impossible to know } \\
\text { if contamination between groups was totally } \\
\text { prevented. The data collected from the first } \\
\text { week of each rotation were not used for anal- } \\
\text { ysis to reduce contamination between groups } \\
\text { at the time of rotation changes" (p. 843, col } \\
2 \text {, para } 4 \text { ) } \\
\text { Detection bias: low } \\
\text { Data were extracted directly from informa- } \\
\text { tion system logs; data collected was objec- } \\
\text { tive - number of logons, etc. "Use of the } \\
\text { personal ID allowed the Ovid system to track } \\
\text { specific information for each of our primary } \\
\text { and secondary outcome measures... These data } \\
\text { were downloaded directly into a data set for } \\
\text { analyses" }\end{array}$ \\
\hline $\begin{array}{l}\text { Incomplete outcome data (attrition bias) } \\
\text { All outcomes }\end{array}$ & Low risk & $\begin{array}{l}\text { "Data directly from Ovid were collected on } \\
47 \text { of } 48 \text { residents. The data on } 1 \text { person in } \\
\text { the control group were lost due to a systems } \\
\text { error" } \\
\text { (p. } 842, \text { col } 1 \text {, para 1) }\end{array}$ \\
\hline Selective reporting (reporting bias) & Low risk & $\begin{array}{l}\text { No protocol available, but appropriate out- } \\
\text { comes were reported }\end{array}$ \\
\hline
\end{tabular}

Interventions to increase the use of electronic health information by healthcare practitioners to improve clinical practice and patient 
Methods
Study design: CRCT

\section{Data collection:}

- Use of the electronic EAS measured by "number of web page hits collected via a software program that tracked cluster-specific IP addresses in batches” (p. 14, para 1)

- Peer-rated EBP behavior was measured using the GAS (p. 12, para 2)

Unit of analysis issues: none suspected due to randomization process; no clusters were lost; baseline characteristics of clusters were documented and differences were not significant

\section{Participants}

\section{Participants:}

allied health practitioners: occupational therapists: IG 23 (31\%); CG 26 (42\%); physiotherapists: IG 16 (22\%); CG 16 (26\%); speech pathologist: IG 20 (27\%); CG $16(25 \%)$ ; psychologist: IG 7 (10\%); CG 1 (2\%); social workers: IG 7 (10\%); CG $3(5 \%)$

Total number randomized: 135; IG 73 (39 Region A; 34 Region B); CG 62 (29 Region C; 33 Region D)

Clusters: 4 based on 4 regions

Baseline characteristics of participants:

Age: not reported

Gender: not reported

Years of experience:

- < 2 years: IG 11 (15\%); CG $16(26 \%)$

- 2-4 years: IG 10 (14\%); CG 12 (19\%)

- 5-9 years: IG 25 (34\%); CG 14 (23\%)

- > 10 years: IG 27 (37\%); CG 20 (32\%)

Setting: community-based cerebral palsy services

Country: Australia

\section{Description of the intervention:}

- Educational session, multifaceted: session incorporated a variety of pedagogic approaches - didactic presentation of information, interaction among participants, role play, and reflection. Content of the session: using the EAS interface; education on levels of evidence (systematic reviews, trials, etc.), and how to apply information from the EAS to clinical decision-making. A knowledge broker was available during the course of the study to mentor participants

- Educational material, provision of: the EAS was provided to participants

- Organizational interventions: policy changes were implemented and included: staff were paid for the time spent learning about EBP; staff permitted dedicated time to learn/practice EBP; work forms, such as client documentation forms, were edited to include reminders to use EAS; outcome measures were embedded in staff workflow; and staff were mentored by knowledge brokers

\section{Type of intervention:}

Educational sessions - group and mentoring

Education material

Organizational interventions

Study period: June 2009 to August 2009

Intervention delivery periods: at beginning of intervention period, 2 days' training; 8 weeks later, 1 day' training

Duration of intervention: 3 days

Data collection time: not clear, e.g. "took place before and after the workshops" (p. 8, 


\begin{tabular}{|c|c|c|}
\hline & \multicolumn{2}{|c|}{$\begin{array}{l}\text { para 1) } \\
\text { Comparison: 3-day workshop structured in the same way as the intervention, but subject } \\
\text { matter was communication and coaching skills. CG were not notified or offered paid } \\
\text { time to implement learning undertaken in their workshop }\end{array}$} \\
\hline Outcomes & \multicolumn{2}{|c|}{$\begin{array}{l}\text { EAS utilization (measured by number of web page hits collected via a software program } \\
\text { that tracked cluster-specific IP addresses in batches) }\end{array}$} \\
\hline Notes & \multicolumn{2}{|c|}{$\begin{array}{l}\text { Baseline characteristics similar: at baseline, participant attributes were mostly comparable } \\
\text { between groups, the exception being prior EBP education attendance ( } 88 \% \text { for IG } \\
\text { compared to } 66 \% \text { for CG) (unclear risk) } \\
\text { Baseline measure of outcomes: no baseline measures of outcome (unclear risk) }\end{array}$} \\
\hline \multicolumn{3}{|l|}{ Risk of bias } \\
\hline Bias & Authors' judgement & Support for judgement \\
\hline $\begin{array}{l}\text { Random sequence generation (selection } \\
\text { bias) }\end{array}$ & Low risk & $\begin{array}{l}135 \text { allied health practitioners from } 4 \text { re- } \\
\text { gions were cluster randomized ( } 4 \text { clusters) } \\
\text { to IG or CG. "An independent officer not } \\
\text { associated with the trial, used computer } \\
\text { generated random numbers, to create four } \\
\text { opaque envelopes based upon simple ran- } \\
\text { domisation. Four geographically distinct } \\
\text { clusters were randomised to the interven- } \\
\text { tion or control group" (p. } 7 \text {, para 2) }\end{array}$ \\
\hline Allocation concealment (selection bias) & Low risk & $\begin{array}{l}\text { "Four geographically distinct clusters were } \\
\text { randomised to the intervention or control } \\
\text { group. Cluster randomisation was chosen } \\
\text { to reduce risk of contamination that may } \\
\text { have occurred if individuals working at the } \\
\text { same site were randomised to different in- } \\
\text { terventions" (p. } 7-8 \text { ) }\end{array}$ \\
\hline
\end{tabular}

Blinding (performance bias and detection Low risk bias)

All outcomes
The CG, which received communication not knowledge translation/searching workshop "was not informed about the EAS (Evidence Alert System), paid EBP (Evidence Based Practice) time, knowledge brokers or mentoring until the end of the trial [which were part of the intervention groups exposure]" (p. 12, para 1)

"Blinding was judiciously applied wherever pragmatically possible, resulting in a single blinded trial. This included:

(1) independent evaluator blinding to group allocation and phase of the trial when 


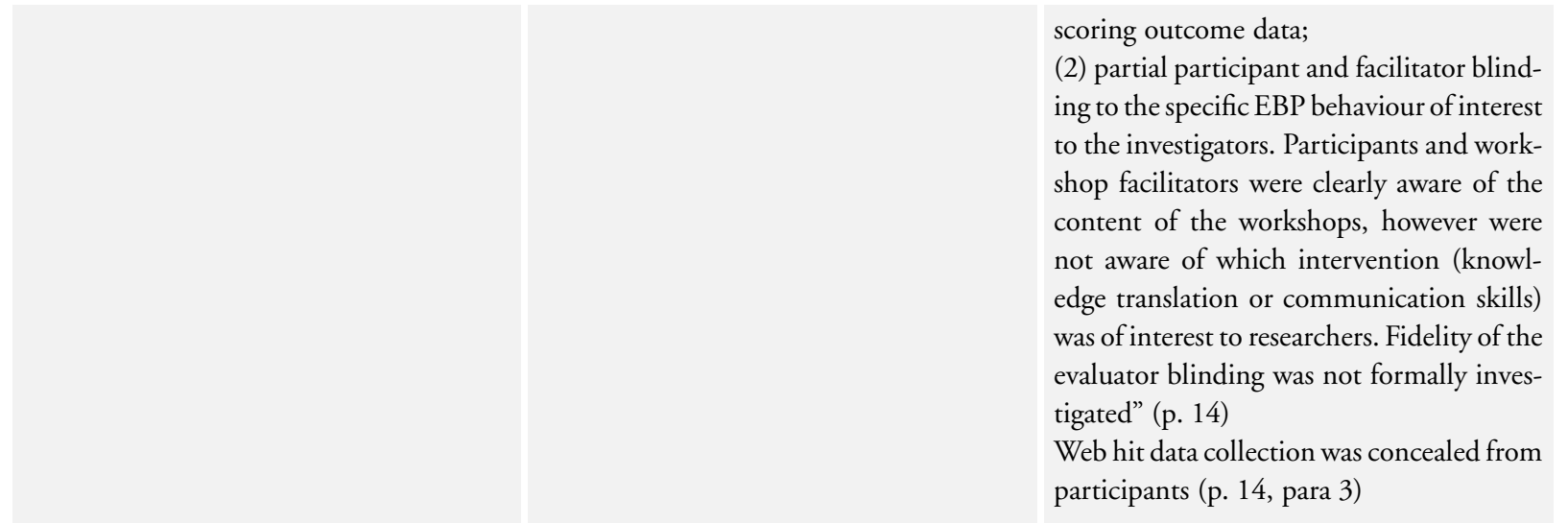

Incomplete outcome data (attrition bias) Low risk All outcomes

For this review, we were interested in use of EHI, and since it was tracked automatically, by IP address associated with clusters, we rate attrition bias as low

For other reviewers, this bias may be considered high because of lost data as follows: peer assessment of EBP behavior for IG: at baseline, data were provided for $52 / 73$ participants; at 8 weeks' post intervention, data were provided for $44 / 73$ participants. For

CG: at baseline $43 / 62$ participants; at 8 weeks post intervention $42 / 62$ participants

\footnotetext{
Selective reporting (reporting bias) Low risk
}

The authors reported on the outcomes described in the Trial Registration record: www.anzctr.org.au/Trial/ Registration/TrialReview.aspx? $\mathrm{id}=336741$

\section{Gulmezoglu 2007}

Methods

\section{Study design: CRCT}

Data collection: data were collected from 1000 consecutive deliveries in each hospital, at baseline and at end of study, or for 6 months, whichever came first. "Each computer has a log file to indicate how many times the program is accessed. We shall analyse the log files as a proxy indicator of RHL use in the intervention hospitals, acknowledging that these may not relate directly to change in behaviour." See method's paper (Gülmezoglu 2004)

Unit of analysis issues: number of hospital was unit of analysis

Participants

Participants: hospital obstetric/gynecologic/maternity units. Physicians, nurses, midwives (any practitioner participating in obstetrics and gynecology or maternity care could participate

Physicians predominated in Mexico (median number of doctors per hospital was 20 
(range 7-102) in IG and 14 (range 8-53) in CG hospitals; in Thailand, median number of doctors was 6 (range 3-18) in IG and 5 (range 2-11) in CG hospitals; nurses were 15 (10-28) in IG and 13 (7-20) in CG hospitals(pp. 19-20)

Total hospitals randomized: 40. IG: 22; CG: 18

Stratification: hospitals were stratified "based on country, type of hospital and number of births per year ( $>5000$ or $<=5000)$ " (p. 17, col 1, para 4)

Thailand stratification: 18. Large: IG 3; CG 3. Small: IG 6; CG 6

Mexico stratification: 22. Large social security hospital: IG 3; CG 2; large public hospital: IG 2; CG 1. Small social security hospital: IG 2; CG 1. Small public hospital: IG 6; CG 5

Setting: 40 hospitals with maternity units with > 1000 deliveries per year. 22 in Mexico City; 18 in the northeast region of Thailand

Countries: Mexico and Thailand

Inclusion criteria: maternity units of hospitals with $>1000$ deliveries per year, not associated directly with a university or other academic/research

department

\section{Description:}

The first part of the intervention, which might be defined as 'organizational', consisted in meeting with hospital directors/heads of obstetrics and gynecology departments with the goal of ensuring organizational buy in

The intervention consisted of 3 interactive workshops using the WHO RHL. The focus of the workshops was to educate users on the content of the RHL and how to use RHL (e.g. "The focus of the workshops was to provide access to knowledge and enable its use" (p. 16, abstract))

A computer and support for using both the computer and RHL were provided at each hospital

Workshop 1: focused on giving information about the project, WHO's role, the principles of evidence-based decision making and presenting RHL

Workshop 2: focused on the content of RHL

Workshop 3: how to implement change

Type of intervention:

Educational sessions (e.g. workshop)

Distribution of educational material (e.g. RHL database, posters, brochures about RHL)

Organizational (e.g. provision of computer hardware)

Organizational (e.g. study authors met with hospital leaders to achieve buy-in/cooperation prior to educational component of intervention)

Study period: October 2001 to October 2002

Intervention delivery periods: over a period of 6 months, at time 0 , after 6 weeks and after 6 months. Note: time delays were experienced in Thailand resulting in up to 6 months between second and third workshop

Duration of intervention: 3 workshops (length of workshop not stated)

Follow-up: 10-12 months from the time of the first workshop; or 4-6 months after the third workshop

Data collection time: 4-6 months following the third workshop

Comparison: no workshops; but access to WHO RHL 
siotomy; uterotonic use after birth; breastfeeding on demand; external cephalic version; iron-folate supplementation; antibiotic use at cesarean section; vacuum extraction for assisted birth

Proportion of staff using RHL once a month measured from baseline to post intervention

Notes

Risk of bias

\begin{tabular}{|c|}
\hline Bias \\
\hline
\end{tabular}

Random sequence generation (selection Low risk bias)
"We used a stratified cluster randomised design, with the hospitals as the units of randomisation. The stratified allocation was based on country, type of hospital and number of births per year ( $>5000$ or 5000 or less) (Figure 1). The random allocation sequence was produced centrally by WHO in Geneva, assigning hospitals at random in each stratum to intervention or control. Country investigators were informed of the allocation status of the hospitals after collection of baseline data was completed and when the first workshop had to be organised as required in the protocol." Note: additional contact with authors provided further information that this was done using PROC PLAN of SAS software
Allocation concealment (selection bias) Low risk

Incomplete outcome data (attrition bias) High risk All outcomes

"Country investigators were informed of the allocation status of the hospitals after collection of baseline data was completed and when the first workshop had to be organized as required by the protocol." Note: additional contact with authors provided further information that the randomization occurred at 1 time point, and allocation was concealed until after this time point

Blinding (performance bias and detection Low risk bias)

All outcomes

"Hospital staff were unaware of the primary outcome practices." "Field workers not involved in the implementation of the trial collected outcome data" (p. 19)

The main outcome measures as designated in the study protocol (e.g. changes to selected clinical practices) were measured for CG and IG in all hospitals 
Gulmezoglu 2007 (Continued)

Process outcomes were measured in 2 ways - by self report (questionnaires), and objectively (e.g. use of the RHL measured by computer log files)

Information on Thai CG was lost

Although the aim was to include all hospital staff in the workshops (IG), attendance rates at workshops varied and there was a large staff turnover, as well as participation from students and staff from other departments. "We aimed to include all staff (doctors, midwives, interns and students) at all three workshops. The highest attendance was at the first workshops, but the other two workshops were also well attended. It was not possible to measure attendance with high precision due to staff turn over and participation of students and staff from other departments (anaesthetists, neonatologists)" (p. 17)

Selective reporting (reporting bias) Low risk

Outcomes delineated in protocol (http:// www.isrctn.com/ISRCTN14055385)

were reported in study

Haynes 2006

Methods

Study design: CRCT

Data collection: individual user logins were tracked by the online system

Unit of analysis issue: clusters were assigned the community (group) level, but primary outcome data were reported on individual participants within each cluster. The authors made this decision based on an analysis of baseline data for the primary outcome measure (number of logins), where they calculated an intracluster correlation coefficient of -0.02 ( $95 \%$ confidence interval -0.16 to 0.12 ) and thus determined that the variation between communities was not important. We agreed that for this outcome, reporting individual login data versus cumulative logins per cluster was acceptable and did not misrepresent the effect of intervention

Participants

Participants: physicians who spent at least $20 \%$ of their time working in general practice or internal medicine, or subspecialties of internal medicine; were available for at least 1 year; were registered with the Northern Ontario Virtual Library; were fluent in English; and used a personal email account at least once per month

Total number randomized: 203. full-service group: 98; self-service group: 105

Clusters: by geographically distinct practice locations referred to as "communities": 10 communities. Full-service and self-service groups each had 5 clusters/communities consisting of 3 small and 2 large clusters

Full-service: 98: 3 small clusters with 15, 18, and 20 physicians; 2 large clusters with 22 and 23 physicians

Self-service: 105: 3 small clusters with 7, 14, and 17 physicians; 2 large clusters with 28

Interventions to increase the use of electronic health information by healthcare practitioners to improve clinical practice and patient 
Haynes 2006 (Continued)

and 39 physicians

Setting: primary care practices; internal medicine practices in northern Ontario, Canada - an area of approximately $800,000 \mathrm{~km}^{2}$ and with a population $<800,000$ inhabitants

Country: Canada

Interventions

\section{Description:}

An electronic database, McMaster PLUS, was added to an existing digital library suite in regional library system. McMaster PLUS was offered in 2 versions, full-service and selfservice. Full-service was the intervention; self-service was the control. McMaster PLUS was provided to groups of practitioners at practice locations in different geographic areas. The full-service version included a unique search interface (search engine) to a new database of critically appraised articles; the self-service version did not. Both the self- and full-service groups had access to usual digital resources such as bibliographic databases (Cochrane Database of Systematic Reviews, MEDLINE, CINAHL, Books at Ovid) through the Ovid interface, MD Consult, and Stat!Ref

Comparison: self-service version of McMaster PLUS

Type of intervention:

Organizational: provision of a new electronic database

Timing: not sure, but outcome data for usage were reported by month

Study period: April 2004 to May 2005

Follow-up: at 19 months after the end of the trial

Outcomes

Use of McMaster PLUS (measured by logins per month)

Notes

Risk of bias

\section{Bias}

Random sequence generation (selection Low risk bias)
Authors' judgement

Support for judgement

Community clusters (participating hospitals/practice sites) were stratified by "the number of participants in each. Each cluster was then assigned a number to conceal the name of the community...and the 4 largest clusters were rank ordered from largest to smallest. Each cluster was randomised to either Full-Service or Self-Service interface based on a table of random numbers...with balancing for each pair of cluster. This process was repeated for the 6 small clusters" (p. 596, col 1, para 3)

Allocation concealment (selection bias) Low risk
"During a pre-randomization baseline period with access only to NOVL [Northern Ontario Virtual Library user data], we assembled trial participants into 10 community clusters by mapping clinical practice locations of PLUS [trial] participants, and 
Haynes 2006 (Continued)

grouping them into non-overlapping clusters with maximized geographic distance between clusters and minimized the variation in numbers of participants in each cluster. Hospital district divisions were consulted about physician practice patterns to make decisions on some cluster designations. ...Since baseline usage patterns showed little inter cluster difference, clusters were ...stratified by the number of participants in each. Each cluster was then assigned a number to conceal the name of the community... and the 4 largest clusters were rank ordered from largest to smallest. Each cluster was randomised to either the Full-Service or Self-Service interface based on a table of random numbers reported by Fleiss, with balancing for each pair of clusters. This process was repeated for the 6 smaller clusters" (p. 595-596, Randomization section)

Baseline characteristics: "Participants were well matched...except that a higher proportion of the participants in the Self-Service group lived in larger communities (64\% vs $46 \%$ for the Full-Service group) (p. 598, col 1, para 2; and Table 2)

cf. Fleiss J. Statistical Methods for Rates and Proportions, 2nd ed. New York: Wiley, 1981

Blinding (performance bias and detection High risk bias)

All outcomes
Detection: high. "All PLUS trial staff except the data analyst were blinded to the allocation of practice communities to FullService or Self-Service trial interfaces until the time of data analysis" (p. 596, col 1, para 3)

Performance: high. "Although physicians could not be blinded to the intervention, the Full Service and Self-Service interfaces were similar in appearance and navigation. ..participants were not told to which group they were assigned. Also, each group's trial period interfaces offered something new compared with the baseline period"

Full servicice group: 5 left the study (1 retired; 1 lost interest; 3 left the eligible area) Self-service group: 4 left the study (3 left the 
Haynes 2006 (Continued)

eligible area; 1 lacked computer literacy)

Selective reporting (reporting bias) Low risk

Utilization of PLUS was the primary outcome measure; this was measured by using the rate of logins per month per user. A login event was defined as a login followed by any system usage (i.e. if any menu items or links were clicked) (p. 597, col 1, para 1)

Jousimaa 2002

Methods

Study design: CRCT

Data collection:

- Review of anonymized patient records (case notes from attending physician). This review was conducted by 1 study author; goal was to assess use of a series of clinical practices. Patient records from physician-reported information-searching consultations were collected. Patient records for the consultation preceding the information searching consultation were also collected

- Self report via questionnaire: for each consultation during which they searched for information, physicians completed a questionnaire to describe why and where they searched, the type of information sought, whether the search identified relevant information, and whether or not the physician complied with the information

- Computer logs: this objective measure of database/electronic information resource use was applied as a means to assess concordance, or lack thereof, between reported searching activities and actual searching activities

Unit of analysis issue: "A retrospective power calculation was done, adjusting for clustering using an intra cluster correlation coefficient (ICC) of 0.015 and an average cluster size of 27 . With 3,484 patients in total, we had $80 \%$ power to detect a $3 \%$ difference between the computer and textbook groups for the common elements of the consultation at the $5 \%$ significance level“

Targeted behavior: use of and compliance with EBMG in patient care

Participants

Participants: newly qualified physicians entering requisite postgraduate patient practice for a period of at least 2 months

Total number randomized: 139; IG: 72; CG: 67

Lost-to follow-up: 0

Baseline characteristics of participants:

Age, mean: IG: 27.3 years; CG 26.9 years

Gender: IG: 69.4\% women; CG: $73.1 \%$ women

Setting: 96 primary health centers

Country: Finland

Interventions

\section{Description:}

an electronic version of the EBMG (a CD-ROM version of EBMG to install on a DC in a consultation room; or a laptop with EBMG installed)

Comparison: a textbook version of the EBMG

Type of intervention:

Organizational: provision of health information to practitioners

Interventions to increase the use of electronic health information by healthcare practitioners to improve clinical practice and patient 
Duration of intervention: 1 month or 50 patient consultations, whichever occurred first

Primary outcome
Outcomes $\begin{aligned} & \text { Physicians' compliance with guidelines based on } 9 \text { measurable elements of care - } \\ & \text { laboratory tests, radiologic tests, physical exam, other exams, procedures, physical } \\ & \text { therapy, non-pharmacologic treatment, referrals - for } 99 \text { common diagnoses } \\ & \text { Secondary outcome } \\ & \bullet \text { Amount of evidence sought based on self reported data (via questionnaire) and } \\ & \text { computer logs }\end{aligned}$

Notes

Non-compliance with the guidelines was classified into 4 categories (none, minor, major, serious) according to their clinical significance (p. 589, para 2)

\section{Risk of bias}

\begin{tabular}{|c|c|c|}
\hline Bias & Authors' judgement & Support for judgement \\
\hline $\begin{array}{l}\text { Random sequence generation (selection } \\
\text { bias) }\end{array}$ & Low risk & $\begin{array}{l}\text { Quote: } \\
\text { participants"were randomised centrally us- } \\
\text { ing computer-generated numbers to re- } \\
\text { ceive either computerised or textbook } \\
\text { guidelines" (p. } 588 \text {, para 4) }\end{array}$ \\
\hline
\end{tabular}

Allocation concealment (selection bias) Unclear risk

Blinding (performance bias and detection High risk bias)

All outcomes
For the purposes of this study, we identified newly qualified physicians who would work in a Finnish health center for at least 2 months during the study period from February 1998 until September 1999 (p. 589, para 2)

Detection bias: low. Assessors evaluating the processes of patient care were "blinded to the study group (computer or textbook, information searching or non-information searching"

"Assessment of patient records/case files for compliance with clinical practices was conducted by one study author who was blinded to whether or not the attending physician had searched for information to support his/her decisions (p. 589, para 2) Performance bias: high. "Prior to the study, the participating physicians agreed not to use the other version of the guidelines if it was available in the health centre" (p. 588, para 2) 
CG: control group; col: column; CPG: clinical practice guidelines; CRCT: cluster randomized controlled trial; DC: desktop computer; EAS: Evidence Alert System; EBM: evidence-based medicine; EBMG: evidence-based medicine guideline; EBP: evidence-based practice; EHI: electronic health information; ER: emergency room; GAS: Goal Attainment Scale; IG: intervention group; IQR: interquartile range; IP: Internet protocol; MC: mobile computer; p.: page; para: paragraph; RCT: randomized controlled trial; RHL: Reproductive Health Library; WBCG: well-built clinical questions.

\section{Characteristics of excluded studies [ordered by study ID]}

\begin{tabular}{ll}
\hline Study & Reason for exclusion \\
\hline Allan 2012 & Design: 1 ongitudinal study ( 0 pre-data points, 1 post-data point) \\
\hline Alper 2005 & No objective outcome measure \\
\hline Bhavnani 2006 & Participants: nursing students not involved in patient care (freshmen) \\
\hline Bowden 2000 & Design: 1 iterature review \\
\hline Butzlaff 2004 & Outcome: only assessed knowledge outcomes \\
\hline Casebeer 2003 & $\begin{array}{l}\text { Outcome: only assessed knowledge outcomes; checked trial report published 2005, but it focused on } \\
\text { continuing medical education vs. electronic health information }\end{array}$ \\
\hline Coiera 2006 & Design: p rospective cohort; not randomized per 2006 protocol \\
\hline Crouse 2005 & Design: editorial \\
\hline
\end{tabular}

D’Alessandro $2004 \quad$ No objective outcome measure 
(Continued)

\begin{tabular}{|c|c|}
\hline Deurenberg 2008 & Study design: semi-structured questionnaire \\
\hline Di Noia 2003 & Participants: not aimed at healthcare professionals in healthcare settings \\
\hline Doran 2010 & No objective outcome measure \\
\hline Doran 2013 & Study design: survey \\
\hline Dykes 2005 & Study design: historical control; no randomization \\
\hline Elhadad 2005 & Intervention: not related to patient care \\
\hline Erickson 1998 & $\begin{array}{l}\text { Reported a non-significant increase of } 0.22 \text { in the mean number of log-ons in the intervention group but } \\
\text { no post-intervention data were provided for the control group }\end{array}$ \\
\hline Estabrooks 2003 & Design: survey \\
\hline Forsetlund 2003 & Participants: public health physicians not involved in patient care \\
\hline Freeth 2001 & Design: post- intervention survey; measured 2 times after, but 0 before (pre) intervention \\
\hline Gardois 2011 & Intervention: case scenarios in a classroom \\
\hline Garg 2003 & Design: literature review \\
\hline Goldstein 2002 & Design: descriptive \\
\hline Grad 2005 & Outcome: only assessed knowledge outcomes patient care outcomes \\
\hline Gruppen 2005 & Participants: students not involved in patient care \\
\hline Gulmezoglu 1997 & Design: editorial \\
\hline Hauser 2007 & Design: single cohort \\
\hline Haynes 1990 & Design: longitudinal, descriptive \\
\hline Helwig 1998 & Design: descriptive \\
\hline Horng 2012 & Design: longitudinal s tudy (1 pre-data point, 1 post-data point) \\
\hline Howe 2001 & Design: narrative \\
\hline Huber 2000 & Design: survey \\
\hline
\end{tabular}

Johnston 2004

Design: survey conducted as part of randomized controlled trial, but data for 1 time point only 
(Continued)

\begin{tabular}{|c|c|}
\hline Kaushal 2010 & $\begin{array}{l}\text { Intervention: included push information (adverse event drug alerts) and searchable information, but } \\
\text { unable to discern which information prescribers used }\end{array}$ \\
\hline Ketikidis 2012 & Design: descriptive \\
\hline Kibbe 2000 & Design: narrative \\
\hline King 2007 & Design: before and after but no control; 1 post-intervention measurement \\
\hline Kirsch 2004 & Design: editorial \\
\hline Kolner 1986 & Outcomes: knowledge only; and intervention - theoretical scenarios not direct patient care \\
\hline Kronick 2003 & $\begin{array}{l}\text { Outcomes: no objective measure of electronic resource use (e.g. before and after survey/questionnaire were } \\
\text { used) }\end{array}$ \\
\hline Ku 2007 & Participants: nursing students, not involved in patient care \\
\hline Langdorf 1995 & Design: 1 ongitudinal study (no pre-data point, 1 post-data point) \\
\hline Lapidus 2009 & $\begin{array}{l}\text { Outcomes: no objective outcome measures ( e.g. all self report). Intervention: focused on use of resources, } \\
\text { not on applying information from resources to patient care }\end{array}$ \\
\hline Leung 2003 & Participants: intervention was educational, no patient care \\
\hline Lindberg 1997 & Design: editorial \\
\hline Malone 2012 & Outcomes: no measure of use of information by practitioners \\
\hline May 2006 & Intervention: patient information not treatment/care information. Design: narrative article \\
\hline Miller 2005 & $\begin{array}{l}\text { Design: not an acceptable study design. Outcomes not relevant. Population did not work directly with } \\
\text { patients }\end{array}$ \\
\hline Mokhtar 2012 & Design: c ross-sectional survey on information behavior (no intervention) \\
\hline Nixon 2000 & Intervention: clinical patient data \\
\hline Noone 1998 & Design: narrative literature review \\
\hline Nussbaum 1998 & Design: descriptive; no intervention \\
\hline Oak 2008 & Outcome : self reporting no objective measures \\
\hline Ogescu 2008 & Design: descriptive; no intervention \\
\hline Oliveri 2004 & Design: $s$ urvey (per translation of methods in full text) \\
\hline
\end{tabular}


(Continued)

\begin{tabular}{|c|c|}
\hline Ozbolt 1993 & Design: narrative literature review \\
\hline Peterson 1983 & Design: d escriptive; i nformation system contained only clinical information \\
\hline Rudin 1996 & Design: narrative article \\
\hline Rudin 1997 & Design: narrative article \\
\hline Sackett 1998 & Design: descriptive feasibility study \\
\hline Safran 1993 & Intervention: clinician reminders \\
\hline Sanchez-Mendiola 2012 & Outcomes: n o objective measure - (e.g. self reported knowledge) \\
\hline Shabi 2011 & Design: survey \\
\hline Sintchenko 2004 & Design: simulated cases \\
\hline Southard 2003 & Outcome: k nowledge only \\
\hline Stewart 2005 & $\begin{array}{l}\text { Intervention: information searching for case studies not patient care during a continuing medical education } \\
\text { course }\end{array}$ \\
\hline Tig 2012 & Design: q uestionnaire \\
\hline Valentino 1974 & Design: $\mathrm{n}$ arrative. Information system contained only clinical data \\
\hline Williams 2013 & Design : $p$ rospective and observational survey \\
\hline Wyatt 1998 & $\begin{array}{l}\text { No usable data: compared access to electronic materials as part of a multifaceted intervention; however, } \\
\text { there was no measure of information retrieval that could be used }\end{array}$ \\
\hline
\end{tabular}

\section{Characteristics of ongoing studies [ordered by study ID]}

\section{Haynes 2014}

Trial name or title Multifaceted Online Interventions to Increase the Quantity and Quality of Searching for Current Best Evidence to Answer Clinical Questions

\begin{tabular}{l|l}
\hline Methods & $\begin{array}{l}\text { Allocation: randomized } \\
\text { Intervention model: factorial assignment } \\
\text { Masking: single blind (investigator) }\end{array}$ \\
\hline Participants & $\begin{array}{l}900 \text { anticipated: } \\
\bullet \text { postgraduate and faculty physicians working in the teaching hospitals and clinics of the Faculty of } \\
\text { Health Sciences, McMaster University, Hamilton, Ontario, Canada }\end{array}$
\end{tabular}


Haynes 2014 (Continued)

\begin{tabular}{l|l}
\hline Interventions & $\begin{array}{l}\text { - Intervention A - online clinical questions recorder } \\
\text { - Intervention B - online evidence retrieval coach } \\
\text { Outcomes }\end{array}$ \\
\hline $\begin{array}{l}\text { Primary: } \\
\text { months). utilization of evidence-based resources as measured by rate of searches/month/user (time frame: } 6 \\
\text { Search (MPFS). When they are signed on their account, the system continuously tracks their searches and } \\
\text { utilization of individual resources. The researchers we will record their utilization over the full duration of } \\
\text { the trial (6 months) and analyze it at the end }\end{array}$ \\
\hline Starting date & January 2014 \\
\hline Contact information & Robert B Haynes, bhaynes@mcmaster.ca \\
\hline Notes & \\
\hline
\end{tabular}

Interventions to increase the use of electronic health information by healthcare practitioners to improve clinical practice and patient 


\section{DATA ANDANALYSES}

This review has no analyses.

\section{ADDITIONAL TABLES}

Table 1. Gulmezoglu and Jousimaa outcomes

\begin{tabular}{|c|c|c|c|c|c|}
\hline \multirow{3}{*}{$\begin{array}{l}\text { Gulmezoglu } 2007 \\
\begin{array}{l}\text { Recommended } \\
\text { practice }\end{array}\end{array}$} & \multicolumn{5}{|c|}{$\begin{array}{l}\text { Practitioners' compliance with } 6 \text { guideline recommended practices; an increase was sought for all prac- } \\
\text { tices }\end{array}$} \\
\hline & \multirow[t]{2}{*}{ Location } & \multicolumn{2}{|c|}{ Rate change } & \multirow{2}{*}{$\begin{array}{l}\text { Difference in } \\
\text { adjusted end of study } \\
\text { rate (IG - CG)* }\end{array}$} & \multirow[t]{2}{*}{ P value } \\
\hline & & IG & CG & & \\
\hline \multirow{2}{*}{$\begin{array}{l}\text { Social support dur- } \\
\text { ing labor }\end{array}$} & Mexico & -2.5 & -1 & 0.1 & 0.58 \\
\hline & Thailand & 18.4 & 5.9 & 18.2 & 0.15 \\
\hline \multirow{2}{*}{$\begin{array}{l}\mathrm{MgSO}_{4} \text { for eclamp- } \\
\text { sia }\end{array}$} & Mexico & 26.5 & 11.1 & 3.8 & 0.88 \\
\hline & Thailand & -26.5 & 17.1 & -11.2 & 0.58 \\
\hline \multirow{2}{*}{$\begin{array}{l}\text { Corticosteroids at }< \\
34 \text { weeks }\end{array}$} & Mexico & 7.9 & 4 & 5.3 & 0.64 \\
\hline & Thailand & 4.4 & 6.5 & 3.8 & 0.63 \\
\hline \multirow[t]{2}{*}{ Selective episiotomy } & Mexico & -5.7 & -5.6 & 3.2 & 0.49 \\
\hline & Thailand & 4.2 & -1.2 & 5.3 & 0.05 \\
\hline \multirow{2}{*}{$\begin{array}{l}\text { Antibiotic use for } \\
\text { cesarean section }\end{array}$} & Mexico & 14.5 & 2.4 & 19 & 0.12 \\
\hline & Thailand & 9.8 & 13.9 & 4.6 & 0.66 \\
\hline \multirow{2}{*}{$\begin{array}{l}\text { Vacuum extraction } \\
\text { delivery }\end{array}$} & Mexico & -0.4 & -0.3 & 0.1 & 0.37 \\
\hline & Thailand & 0.1 & 0.4 & 0 & 0.95 \\
\hline MEDIAN & & 4.3 & 3.2 & 3.8 & - \\
\hline Jousimaa 2002 & \multicolumn{3}{|c|}{$\begin{array}{l}\text { Practitioners' compliance with } 9 \text { guideline recom- } \\
\text { mended practices: \% of guideline compliant consulta- } \\
\text { tions }\end{array}$} & \multirow[t]{2}{*}{ Odds ratio $(95 \% \mathrm{CI})$} & \multirow[t]{2}{*}{ ICC } \\
\hline $\begin{array}{l}\text { Recommended } \\
\text { practice per guide- } \\
\text { lines }\end{array}$ & IG & & CG & & \\
\hline Laboratory exams & $90.3 \%(1481 / 1640)$ & & $89.7 \%(1372 / 1529)$ & 1.07 (0.79 to 1.44$)$ & 0.015 \\
\hline Radiologic exams & $93.8 \%(1504 / 1604)$ & & $93.3 \%(1416 / 1518)$ & $1.09(0.81$ to 1.46$)$ & 0 \\
\hline
\end{tabular}


Table 1. Gulmezoglu and Jousimaa outcomes

(Continued)

\begin{tabular}{|c|c|c|c|c|}
\hline Physical exams & $92.8 \%(1494 / 1610)$ & $94.6 \%(1461 / 1545)$ & $0.74(0.51$ to 1.06$)$ & 0.015 \\
\hline Other exams & $74.8 \%(235 / 314)$ & $80.8 \%(248 / 307)$ & $0.71(0.43$ to 1.36$)$ & 0.021 \\
\hline Procedures & $77.6 \%(152 / 196)$ & $81.9 \%(140 / 171)$ & $0.77(0.43$ to 1.36$)$ & 0 \\
\hline Physical therapy & $78.6 \%(77 / 98)$ & $80.6 \%(83 / 103)$ & $0.88(0.34$ to 2.32$)$ & 0.195 \\
\hline $\begin{array}{l}\text { Nonpharmacologic } \\
\text { treatment }\end{array}$ & $87.0 \%(80 / 92)$ & $90.2 \%(110 / 122)$ & $0.73(0.22$ to 2.41$)$ & 0.058 \\
\hline $\begin{array}{l}\text { Pharmacologic } \\
\text { treatment }\end{array}$ & $84.1 \%(1391 / 1654)$ & $86.1 \%(1350 / 1568)$ & 0.85 (0.67 to 1.09$)$ & 0.01 \\
\hline Referrals & $96.1 \%(1619 / 1684)$ & $95.6 \%(1508 / 1578)$ & $1.13(0.79$ to 1.63$)$ & 0.002 \\
\hline
\end{tabular}

CG: control group; CI: confidence interval; ICC: intracluster correlation coefficient; IG: intervention group.

\section{A P PENDICES}

\section{Appendix I. MEDLINE search strategy}

Ovid MEDLINE(R) In-Process \& Other Non-Indexed Citations and Ovid MEDLINE(R) <1946 to Present>

1 *Decision Making/ (24071)

2 Decision Making, Computer-Assisted/ (2262)

3 *Decision Support Systems, Clinical/ (2888)

$4 *$ “Information Storage and Retrieval"/ (8152)

$5 *$ information services/ (8698)

6 *Information Systems/ (11748)

7 *Information Dissemination/ (4028)

$8 *$ Evidence-Based Medicine/ (17675)

9 ((decisionmaking or decision making) adj3 (support or tool* or system* or assisted)).ti,ab. (2658)

10 decision support.ti. (2302)

11 (information adj3 (tool* or system* or service*)).ti,ab. (29844)

12 ((ask* or formulat* or answer*) adj3 (question* or query or queries)).ti,ab. (43497)

13 (search* adj5 (information or evidence)).ti,ab. (5883)

14 (access* adj5 (information or evidence or knowledge)).ti,ab. (11220)

15 (barrier* adj5 (information or evidence or knowledge)).ti,ab. (2842)

16 (uptake adj5 (information or evidence or knowledge)).ti,ab. (2076)

17 (engage* adj3 (information or evidence or knowledge)).ti,ab. (393)

18 (educat* adj3 (information or evidence or knowledge)).ti,ab. (7234)

19 (training adj3 (information or evidence or knowledge)).ti,ab. (3359)

20 (workshop* adj3 (information or evidence or knowledge)).ti,ab. (274)

Interventions to increase the use of electronic health information by healthcare practitioners to improve clinical practice and patient 
21 (course* adj3 (information or evidence or knowledge)).ti,ab. (1620)

22 (promot* adj3 (information or evidence or knowledge)).ti,ab. (3191)

23 (support adj3 (information or evidence or knowledge)).ti,ab. (24789)

24 (evidence based adj (medicine or practice or healthcare or health care)).ti,ab. (11984)

25 Point of care systems/ (5817)

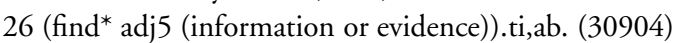

27 or/1-26 (237543)

28 *Internet/ (22558)

$29 *$ Online systems/ (2923)

30 *Computers, handheld/ (1268)

31 Databases, Bibliographic/ (3681)

32 Databases, Factual/ (36228)

33 Medline/ (3943)

34 medline.ti,ab. (45963)

35 embase.ti,ab. (19768)

36 cinahl.ti,ab. (7151)

37 cochrane library.ti,ab. (9451)

38 (psycinfo or psyclit).ti,ab. (6539)

39 pubmed.ti,ab. (19123)

40 uptodate.ti,ab. (80)

41 dynamed.ti,ab. (16)

42 Inforetriever.ti,ab. (10)

43 "McMaster Plus".ti,ab. (3)

44 "map of medicine".ti,ab. (4)

45 ((clinical evidence or best practice) and bmj).ti,ab. (61)

46 emedicine.ti,ab. (19)

47 EBMguidelines.ti,ab. (2)

48 acp journal club.ti,ab. (604)

49 who reproductive health library.ti,ab. (10)

50 nhs evidence.ti,ab. (32)

51 ((electronic or online or on-line or internet or web* or intranet) adj3 (library or libraries)).ti,ab. (862)

52 (elibrary or e-library).ti,ab. (20)

53 ((electronic or online or on-line or internet or web* or intranet) adj3 information).ti,ab. (5692)

54 ((electronic or online or on-line or internet or web* or intranet) adj3 resource*).ti,ab. (3295)

55 (digital adj3 (library or libraries)).ti,ab. (279)

56 ((electronic or online or on-line or internet or web* or intranet) adj3 database*).ti,ab. (11156)

57 (ebsco or ebscohost).ti,ab. (437)

58 ovid.ti,ab. (2225)

59 (silverplatter or silver platter).ti,ab. (73)

60 ((tailor* or evidence* or computer* or electronic or online or on-line or internet or web* or digital) adj3 (synopsis or synopses)).ti,ab. (22)

61 ((tailor* or evidence* or computer* or electronic or online or on-line or internet or web* or digital) adj3 (summary or summaires)).ti,ab. (1437)

62 ((computer* or electronic or online or on-line or internet or web* or digital) adj3 guideline*).ti,ab. (731)

63 ((computer* or electronic or online or on-line or internet or web* or digital) and guideline*).ti. (500)

64 ((search* or find* or access* or barrier* or uptake) adj3 information adj3 (bedside* or bed-side* or "point of care")).ti,ab. (28)

65 ((computer? or information technology or wireless technology or PDA or handheld or blackberr\$) adj3 (bedside* or bed-side* or "point of care")).ti,ab. (188)

66 or/28-65 (141110)

6727 and 66 (20519)

68 Information Seeking Behavior/ (301)

69 (information adj3 seek).ti,ab. (760)

70 ((find or finding) adj2 information).ti,ab. (924)

Interventions to increase the use of electronic health information by healthcare practitioners to improve clinical practice and patient 
71 ((information technology or wireless technology or PDA or handheld or blackberr\$) adj10 ((clinical or physician? or doctor? or patient care) adj decision making)).ti,ab. (15)

72 (access adj2 evidence adj4 (physician? or doctor? or clinician?)).ti,ab. (8)

73 (find $\$$ information adj4 (physician? or doctor? or clinician?)).ti,ab. (5)

74 (search* adj2 time adj8 (physician? or doctor? or clinician?)).ti,ab. (7)

75 (portal adj3 (physician? or doctor? or clinician?)).ti,ab. (26)

76 ((effectiv* or efficient or efficienc* or improv* or teach* or learn*) adj2 (literature search* or database search* ${ }^{*}$ or information retriev* or ((online or web* or electronic) adj2 information))).ti,ab. (184)

7767 or 68 or 69 or 70 or 71 or 72 or 73 or 74 or 75 or $76(22108)$

78 (randomized controlled trial or controlled clinical trial).pt. or randomized.ab. or placebo.ab. or clinical trials as topic.sh. or randomly.ab. or trial.ti. (798992)

79 exp animals/ not humans.sh. (3760079)

8078 not 79 [Cochrane RCT Filter 6.4.d Sens/Precision Maximizing] (738546)

81 intervention?.ti. or (intervention? adj6 (clinician? or collaborat $\$$ or community or complex or DESIGN\$ or doctor? or educational or family doctor? or family physician? or family practitioner? or financial or GP or general practice? or hospital? or impact? or improv\$ or individuali?e? or individuali?ing or interdisciplin $\$$ or multicomponent or multi-component or multidisciplin $\$$ or multi-disciplin $\$$ or multifacet $\$$ or multi-facet $\$$ or multimodal $\$$ or multi-modal $\$$ or personali?e? or personali?ing or pharmacies or pharmacist? or pharmacy or physician? or practitioner? or prescrib\$ or prescription? or primary care or professional\$ or provider? or regulatory or regulatory or tailor\$ or target\$ or team $\$$ or usual care)).ab. (131488)

82 (pre-intervention? or preintervention? or “pre intervention?” or post-intervention? or postintervention? or “post intervention?”).ti,ab. [added 2.4] (7594)

83 (hospital\$ or patient?).hw. and (study or studies or care or health $\$$ or practitioner? or provider? or physician? or nurse? or nursing or doctor?).ti,hw. (656215)

84 demonstration project?.ti,ab. (1771)

85 (pre-post or "pre test\$" or pretest\$ or posttest\$ or “post test\$" or (pre adj5 post)).ti,ab. (54133)

86 (pre-workshop or post-workshop or (before adj3 workshop) or (after adj3 workshop)).ti,ab. (491)

87 trial.ti. or ((study adj3 aim?) or "our study").ab. (512662)

88 (before adj10 (after or during)).ti,ab. (320579)

89 ("quasi-experiment\$” or quasiexperiment\$ or “quasi random\$” or quasirandom\$ or "quasi control\$” or quasicontrol\$ or ( quasi\$ or experimental) adj3 (method\$ or study or trial or design\$))).ti,ab,hw. [ML] (89711)

90 (“time series" adj2 interrupt\$).ti,ab,hw. [ML] (738)

91 (time points adj3 (over or multiple or three or four or five or six or seven or eight or nine or ten or eleven or twelve or month\$ or hour? or day? or "more than")).ab. (7161)

92 pilot.ti. (32982)

93 Pilot projects/ [ML] (72166)

94 (clinical trial or controlled clinical trial or multicenter study).pt. [ML] (585168)

95 (multicentre or multicenter or multi-centre or multi-center).ti. (24510)

96 random\$.ti,ab. or controlled.ti. (649913)

97 (control adj3 (area or cohort? or compare? or condition or design or group? or intervention? or participant? or study)).ab. not (controlled clinical trial or randomized controlled trial).pt. [ML] (353964)

98 “comment on".cm. or review.ti,pt. or randomized controlled trial.pt. [ML] (2638447)

99 review.ti. [EM] (221797)

100 (rat or rats or cow or cows or chicken? or horse or horses or mice or mouse or bovine or animal?).ti. (1273249)

101 exp animals/ not humans.sh. [ML] (3760079)

102 (animal\$ not human\$).sh,hw. [EM] (3666035)

103 *experimental design/ or *pilot study/ or quasi experimental study/ [EM] (18314)

104 (“quasi-experiment\$” or quasiexperiment\$ or “quasi random\$” or quasirandom\$ or “quasi control\$” or quasicontrol\$ or ((quasi\$ or experimental) adj3 (method\$ or study or trial or design\$))).ti,ab. [EM] (89711)

105 (“time series" adj2 interrupt\$).ti,ab. [EM] (738)

106 (or/81-92,95-97) or experimental design/ or between groups design/ or quantitative methods/ or quasi experimental methods/ [PsycInfo] (2446549)

107 exp animals/ or animal?.ti,id,hw. [PsycInfo] (16226114)

108 (or/81-97) not (or/98,100-101) [EPOC Methods Filter 2.4 Medline] (1869345)

Interventions to increase the use of electronic health information by healthcare practitioners to improve clinical practice and patient 
109 (or/81-88,91-92,95-96,103-105) not (or/99,102) [EPOC Methods Filter 2.4 EMBASE] (1891709)

110106 not (or/99-100,107) [EPOC Methods Filter 2.4 PsycInfo] (280322)

11177 and 80 [RCT results] (2923)

112 (77 and 108) not 111 [EPOC results] (3380) [A

\section{Appendix 2. CINAHL search strategy}

A copy of the CINAHL strategy was not saved; we identified 1105 citations from CINAHL.

\section{Appendix 3. Cochrane Central Register of Controlled Trials search strategy}

Cochrane Central Register of Controlled Trials (Cochrane Library, Wiley)

\#1 MeSH descriptor Decision Making, this term only \#2 MeSH descriptor Decision Making, Computer-Assisted, this term only \#3 MeSH descriptor Decision Support Systems, Clinical explode all trees \#4 MeSH descriptor Information Storage and Retrieval, this term only \#5 MeSH descriptor Information Services, this term only \#6 MeSH descriptor Information Systems, this term only \#7 MeSH descriptor Information Dissemination explode all trees \#8 MeSH descriptor Evidence-Based Medicine, this term only \#9 ((decisionmaking or decision making) near3 (support or tool* or system* or assisted)):ti,ab,kw $\# 10$ (decision support):ti \#11 (information near3 (tool* or system* or service*)):ti,ab,kw \#12 ((ask* or formulat* or answer*) near3 (question* or query or queries)):ti,ab,kw \#13 (search* near5 (information or evidence)):ti,ab,kw \#14 (find* near5 (information or evidence)):ti,ab,kw 15 (access* near5 (information or evidence or knowledge)):ti,ab,kw \#16 (barrier* near5 (information or evidence or knowledge)):ti,ab,kw \#17 (uptake near5 (information or evidence or knowledge)):ti,ab,kw \#18 (engage* near3 (information or evidence or knowledge)):ti,ab, kw \#19 (educat* near3 (information or evidence or knowledge)):ti,ab,kw \#20 (training near3 (information or evidence or knowledge)):ti,ab, kw \#21 (workshop* near3 (information or evidence or knowledge)):ti,ab, kw \#22 (course* near3 (information or evidence or knowledge)):ti,ab,kw \#23 (promot* near3 (information or evidence or knowledge)):ti,ab,kw \#24 (support near3 (information or evidence or knowledge)):ti,ab,kw \#25 (evidence based near (medicine or practice or healthcare or health care)):ti,ab,kw \#26 MeSH descriptor Point-of-Care Systems explode all trees \#27 \#1 OR \#2 OR \#3 OR \#4 OR \#5 OR \#6 OR \#7 OR \#8 OR \#9 OR \#11 OR \#12 OR \#13 OR \#14 OR \#15 OR \#16 OR \#17 OR \#18 OR \#19 OR \#20 OR \#21 OR \#22 OR \#23 OR \#24 OR \#25 OR \#26)

\#28 MeSH descriptor Internet, this term only \#29 MeSH descriptor Online Systems explode all trees \#30 MeSH descriptor Computers, Handheld explode all trees \#31 MeSH descriptor Databases, Bibliographic explode all trees \#32 MeSH descriptor Databases, Factual, this term only \#33 (medline OR embase OR cinahl OR “cochrane library” OR psycinfo OR psyclit OR pubmed OR uptodate OR dynamed OR inforetriever OR "mcmaster plus" OR "map of medicine” OR ((clinical evidence OR best practice ) AND bmj ) OR emedicine OR ebmguidelines OR “acp journal club” OR “who reproductive health library” OR “nhs evidence”):ti,ab,kw \#34 ((electronic or online or on-line or internet or web* or intranet) near3 (library or libraries)):ti,ab,kw \#35 (elibrary or e-library):ti,ab,kw

36 ((electronic or online or on-line or internet or web* or intranet) near3 information):ti,ab,kw \#37 ((electronic or online or on-line or internet or web* or intranet) near3 resource*):ti,ab,kw

Interventions to increase the use of electronic health information by healthcare practitioners to improve clinical practice and patient 
\#38 (digital near3 (library or libraries)):ti,ab,kw

\#39 ((electronic or online or on-line or internet or web* or intranet) near3 database*):ti,ab,kw

\#40 (ebsco or ebscohost):ti,ab,kw

\#41 (ovid):ti,ab,kw

\#42 (silverplatter or silver platter):ti,ab,kw

\#43 ((tailor* or evidence* or computer* or electronic or online or on-line or internet or web* or digital) near3 (synopsis or synopses)):

ti,ab,kw

\#44 ((tailor* or evidence* or computer* or electronic or online or on-line or internet or web* or digital) near3 (summary or summaires)):

ti,ab,kw

\#45 ((computer* or electronic or online or on-line or internet or web* or digital) near3 guideline*):ti,ab,kw

\#46 ((computer* or electronic or online or on-line or internet or web* or digital) and guideline*):ti

\#47 ((search* or find* or access* or barrier* or uptake) near3 information near3 (bedside* or bed-side* or "point of care")):ti,ab,kw

\#48 ((computer* or information technology or wireless technology or PDA or handheld or blackberry) near3 (bedside* or bed-side* or "point of care")):ti,ab,kw

\#49 (\#28 OR \#29 OR \#30 OR \#31 OR \#32 OR \#33 OR \#34 OR \#35 OR \#36 OR \#37 OR \#38 OR \#39 OR \#40 OR \#41 OR \#42

OR \#43 OR \#44 OR \#45 OR \#46 OR \#47 OR \#48)

\#50 (\#27 AND \#49)

\#51 MeSH descriptor Information Seeking Behavior explode all trees

\#52 (information near3 seek):ti,ab,kw

\#53 ((find or finding) near2 information):ti,ab,kw

\#54 ((information technology or wireless technology or PDA or handheld or blackberr\$) near10 ((clinical or physician? or doctor? or patient care) near decision making)):ti,ab,kw

\#55 (access near2 evidence near4 (physician* or doctor* $^{*}$ or clinician*)):ti,ab,kw

\#56 (find* information near4 (physician* or doctor* or clinician*)):ti,ab,kw

\#57 (search* near2 time near8 (physician* or doctor* or clinician*)):ti,ab,kw

\#58 (portal near3 (physician* or doctor* or clinician*)):ti,ab,kw

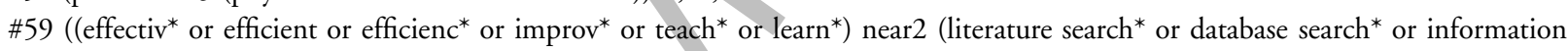
retriev* or ((online or web* or electronic) near2 information) )):ti,ab,kw

\#60 (\#50 OR \#51 OR \#52 OR \#43 OR \#54 OR \#55 OR \#56 OR \#57 OR \#58 OR \#59)

\#61 (\#60), from 2008 to 2012

\section{Appendix 4. EMBASE search strategy}

Embase Classic+Embase <1947 to 2012 August 07>

$1 *$ decision making/ (36034)

$2 *$ medical decision making/ (6111)

$3 *$ decision support system/ (5726)

$4 *$ information service/ (7197)

$5 *$ information retrieval/ (6948)

$6 *$ information dissemination/ (2702)

7 *information system/ or *hospital information system/ or *medical information system/ or *nursing information system/ (32969)

8 * evidence based medicine/ (15352)

9 ((decisionmaking or decision making) adj3 (support or tool* or system* or assisted)).ti,ab. (3492)

10 decision support.ti. (2663)

11 (information adj3 (tool* or system* or service*)).ti,ab. (37278)

12 ((ask* or formulat* or answer*) adj3 (question* or query or queries)).ti,ab. (59595)

13 (search* adj5 (information or evidence)).ti,ab. (7477)

14 (find* adj5 (information or evidence)).ti,ab. (37158)

15 (access* adj5 (information or evidence or knowledge)).ti,ab. (13481)

16 (barrier* adj5 (information or evidence or knowledge)).ti,ab. (3382)

17 (uptake adj5 (information or evidence or knowledge)).ti,ab. (2694)

Interventions to increase the use of electronic health information by healthcare practitioners to improve clinical practice and patient 
18 (engage* adj3 (information or evidence or knowledge)).ti,ab. (471)

19 (educat* adj3 (information or evidence or knowledge)).ti,ab. (8647)

20 (training adj3 (information or evidence or knowledge)).ti,ab. (4379)

21 (workshop* adj3 (information or evidence or knowledge)).ti,ab. (376)

22 (course* adj3 (information or evidence or knowledge)).ti,ab. (2312)

23 (promot* adj3 (information or evidence or knowledge)).ti,ab. (3767)

24 (support adj3 (information or evidence or knowledge)).ti,ab. (31093)

25 (evidence based adj (medicine or practice or healthcare or health care)).ti,ab. (15108)

26 Point of care systems/ (16563)

271 or 2 or 3 or 4 or 5 or 6 or 7 or 8 or 9 or 10 or 11 or 12 or 13 or 14 or 15 or 16 or 17 or 18 or 19 or 20 or 21 or 22 or 23 or 24 or

25 or $26(309224)$

$28 *$ Internet/ (21654)

$29 *$ online system/ (3671)

$30 *$ microcomputer/ (6414)

31 exp *bibliographic database/ (2514)

$32 *$ factual database/ (4762)

$33^{*}$ knowledge base/ (319)

34 medline.ti,ab. (55653)

35 embase.ti,ab. (23850)

36 cinahl.ti,ab. (7992)

37 cochrane library.ti,ab. (11202)

38 (psycinfo or psyclit).ti,ab. (4794)

39 pubmed.ti,ab. (24739)

40 uptodate.ti,ab. (128)

41 dynamed.ti,ab. (23)

42 Inforetriever.ti,ab. (11)

43 "McMaster Plus".ti,ab. (3)

44 "map of medicine".ti,ab. (8)

45 ((clinical evidence or best practice) and bmj).ti,ab. (24)

46 emedicine.ti,ab. (26)

47 EBMguidelines.ti,ab. (2)

48 acp journal club.ti,ab. (223)

49 who reproductive health library.ti,ab. (17)

50 nhs evidence.ti,ab. (47)

51 ((electronic or online or on-line or internet or web* or intranet) adj3 (library or libraries)).ti,ab. (1016)

52 (elibrary or e-library).ti,ab. (24)

53 ((electronic or online or on-line or internet or web* or intranet) adj3 information).ti,ab. (7038)

54 ((electronic or online or on-line or internet or web* or intranet) adj3 resource*).ti,ab. (3976)

55 (digital adj3 (library or libraries)).ti,ab. (319)

56 ((electronic or online or on-line or internet or web* or intranet) adj3 database*).ti,ab. (14329)

57 (ebsco or ebscohost).ti,ab. (520)

58 ovid.ti,ab. (2912)

59 (silverplatter or silver platter).ti,ab. (74)

60 ((tailor* or evidence* or computer* or electronic or online or on-line or internet or web* or digital) adj3 (synopsis or synopses)).ti,ab. (35)

61 ((tailor* or evidence* or computer* or electronic or online or on-line or internet or web* or digital) adj3 (summary or summaires)).ti,ab. (1811)

62 ((computer* or electronic or online or on-line or internet or web* or digital) adj3 guideline*).ti,ab. (930)

63 ((computer* or electronic or online or on-line or internet or web* or digital) and guideline*).ti. (589)

64 ((search* ${ }^{*}$ or find* or access* or barrier* or uptake) adj3 information adj3 (bedside* or bed-side* or "point of care")).ti,ab. (30)

65 ((computer? or information technology or wireless technology or PDA or handheld or blackberr $\$$ ) adj3 (bedside* or bed-side* or "point of care")).ti,ab. (228)

Interventions to increase the use of electronic health information by healthcare practitioners to improve clinical practice and patient 
6628 or 29 or 30 or 31 or 32 or 33 or 34 or 35 or 36 or 37 or 38 or 39 or 40 or 41 or 42 or 43 or 44 or 45 or 46 or 47 or 48 or 49 or 50 or 51 or 52 or 53 or 54 or 55 or 56 or 57 or 58 or 59 or 60 or 61 or 62 or 63 or 64 or 65 (131328)

6727 and $66(20463)$

68 *information seeking/ (146)

69 (information adj3 seek).ti,ab. (894)

70 ((find or finding) adj2 information).ti,ab. (1190)

71 ((information technology or wireless technology or PDA or handheld or blackberr\$) adj10 ((clinical or physician? or doctor? or patient care) adj decision making)).ti,ab. (15)

72 (access adj2 evidence adj4 (physician? or doctor? or clinician?)).ti,ab. (10)

73 (find\$ information adj4 (physician? or doctor? or clinician?)).ti,ab. (5)

74 (search* adj2 time adj8 (physician? or doctor? or clinician?)).ti,ab. (6)

75 (portal adj3 (physician? or doctor? or clinician?)).ti,ab. (36)

76 ((effectiv* $^{*}$ or efficient or efficienc* or improv* or teach* or learn*) adj2 (literature search* or database search* ${ }^{*}$ or information retriev* or ((online or web* or electronic) adj2 information))).ti,ab. (217)

7767 or 68 or 69 or 70 or 71 or 72 or 73 or 74 or 75 or $76(22306)$

78 controlled clinical trial/ or controlled study/ or randomized controlled trial/ [EM] (3912274)

79 (book or conference paper or editorial or letter or review).pt. not randomized controlled trial/ [Per BMJ Clinical Evidence filter] (3787765)

80 (random sampl\$ or random digit\$ or random effect\$ or random survey or random regression).ti,ab. not randomized controlled trial/ [Per BMJ Clinical Evidence filter] (45876)

81 (animal\$ not human\$).sh,hw. (3737669)

8278 not (or/79-81) [Trial filter per BMJ CLinical Evidence] (2564121)

83 intervention?.ti. or (intervention? adj6 (clinician? or collaborat\$ or community or complex or DESIGN\$ or doctor? or educational or family doctor? or family physician? or family practitioner? or financial or GP or general practice? or hospital? or impact? or improv\$ or individuali?e? or individuali?ing or interdisciplin $\$$ or multicomponent or multi-component or multidisciplin\$ or multi-disciplin\$ or multifacet $\$$ or multi-facet $\$$ or multimodal $\$$ or multi-modal $\$$ or personali?e? or personali?ing or pharmacies or pharmacist? or pharmacy or physician? or practitioner? or prescrib $\$$ or prescription? or primary care or professional $\$$ or provider? or regulatory or regulatory or tailor $\$$ or target $\$$ or team $\$$ or usual care) $)$.ab. (169481)

84 (pre-intervention? or preintervention? or “pre intervention?” or post-intervention? or postintervention? or “post intervention?”).ti,ab. [added 2.4] (9761)

85 (hospital\$ or patient?).hw. and (study or studies or care or health\$ or practitioner? or provider? or physician? or nurse? or nursing or doctor?).ti,hw. (1402713)

86 demonstration project?.ti,ab. (2196)

87 (pre-post or “pre test\$” or pretest\$ or posttest\$ or “post test\$” or (pre adj5 post)).ti,ab. (77200)

88 (pre-workshop or post-workshop or (before adj3 workshop) or (after adj3 workshop)).ti,ab. (652)

89 trial.ti. or ((study adj3 aim?) or “our study”).ab. (699024)

90 (before adj10 (after or during)).ti,ab. (430396)

91 ("quasi-experiment\$” or quasiexperiment\$ or “quasi random\$” or quasirandom\$ or “quasi control\$” or quasicontrol\$ or ((quasi\$ or experimental) adj3 (method\$ or study or trial or design\$))).ti,ab,hw. [ML] (205244)

92 (“time series" adj2 interrupt\$).ti,ab,hw. [ML] (872)

93 (time points adj3 (over or multiple or three or four or five or six or seven or eight or nine or ten or eleven or twelve or month\$ or hour? or day? or "more than")).ab. (9480)

94 pilot.ti. (42866)

95 Pilot projects/ [ML] (58437)

96 (clinical trial or controlled clinical trial or multicenter study).pt. [ML] (0)

97 (multicentre or multicenter or multi-centre or multi-center).ti. (33442)

98 random\$.ti,ab. or controlled.ti. (819604)

99 (control adj3 (area or cohort? or compare? or condition or design or group? or intervention? or participant? or study)).ab. not (controlled clinical trial or randomized controlled trial).pt. [ML] (540491)

100 “comment on".cm. or review.ti,pt. or randomized controlled trial.pt. [ML] (2039771)

101 review.ti. [EM] (280385)

102 (rat or rats or cow or cows or chicken? or horse or horses or mice or mouse or bovine or animal?).ti. (1577506)

103 exp animals/ not humans.sh. [ML] (1792934)

Interventions to increase the use of electronic health information by healthcare practitioners to improve clinical practice and patient 
104 (animal\$ not human\$).sh,hw. [EM] (3737669)

105 *experimental design/ or *pilot study/ or quasi experimental study/ [EM] (4936)

106 (“quasi-experiment\$” or quasiexperiment\$ or “quasi random\$” or quasirandom\$ or “quasi control\$” or quasicontrol\$ or ((quasi\$ or experimental) adj3 (method\$ or study or trial or design\$))).ti,ab. [EM] (117873)

107 (“time series" adj2 interrupt\$).ti,ab. [EM] (872)

108 (or/83-94,97-99) or experimental design/ or between groups design/ or quantitative methods/ or quasi experimental methods/ [PsycInfo] (3620774)

109 exp animals/ or animal?.ti,id,hw. [PsycInfo] (4541305)

110 (or/83-99) not (or/100,102-103) [EPOC Methods Filter 2.4 Medline] (3126863)

111 (or/83-90,93-94,97-98,105-107) not (or/101,104) [EPOC Methods Filter 2.4 EMBASE] (2899837)

112108 not (or/101-102,109) [EPOC Methods Filter 2.4 PsycInfo] (3125447)

11377 and 82 [RCT results] (2192)

114 (77 and 111) not 113 [EPOC Results] (5881)

\section{Appendix 5. Library and Information Science Abstracts (LISA) search strategy}

Friday, February 10, 2012 1:43:11 PM

Interface: - EBSCOhost

Search Screen: - Advanced Search

Database: - Library Literature \& Information Science Full Text (H.W. Wilson)

\begin{tabular}{lll}
\hline \# & Query & Results \\
\hline
\end{tabular}

S17 S1 or S2 or S3 or S4 or S5 or S6 or S7 or S8 or S9 or S10 or 136

$\mathrm{S} 11$ or $\mathrm{S} 12$ or $\mathrm{S} 13$ or $\mathrm{S} 14$ or $\mathrm{S} 15$ or $\mathrm{S} 16$

S16 ( SU ( Information retrieval or databases or Information stor- 30 age \& retrieval systems ) AND SU ( physician? or doctor? or allied health* or (health* w2 (worker? or staff or practitioner? )) or nurse or nurses ) ) OR ( SU ( Information retrieval or databases or Information storage $\&$ retrieval systems ) AND $\mathrm{AB}$ ( physician? or doctor? or allied health* or (health* w2 (worker? or staff or practitioner?)) or nurse or nurses ) )

S15 SU electronic information resources AND TI ( physician? or 13 doctor? or clinician? or nurse or nurses or (heath* $\mathrm{n} 2$ (worker? or staff or professional? or practitioner?)) )

S14 SU electronic information resources AND SU ( physician? or 2 doctor? or clinician? or nurse or nurses or (heath* $\mathrm{n} 2$ (worker? or staff or professional? or practitioner?)) )

S13 (study or trial? or pilot* or change? or changing or effectiveness 14 or improv* or increas* or random* or control? or controlled or cluster ) AND S12 
S12 SU ( Information retrieval or databases or Information storage 31 $\&$ retrieval systems ) AND Ti ( physician? or doctor? or allied health* or (health* w2 (worker? or staff or practitioner?)) or nurse or nurses )

S11 SU Information retrieval AND SU ( physician? or doctor? or 3 allied health* or (health* w2 (worker? or staff or practitioner? )) or nurse or nurses )

S10 (((health* worker?) or (health* professional?) or (health* prac- 7 titioner?)) N4 (information seek* or information retriev* or

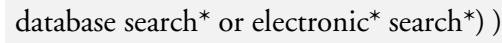

S9 TI ( physician* AND information ) OR AB ( ((information seek* or searching or database* or electronic information or evidence-based information or evidence-based resource*) n5 (clinician* ${ }^{*}$ or doctor ${ }^{*}$ or practitioner* or nurse or nurses or allied health* or physician*)) )

S8 TI ( physician* or doctor* or clinician*) AND AB ( informa- 9 tion seek* or searching or database* ${ }^{*}$ or electronic information or evidence-based information or evidence-based resource* ${ }^{*}$ )

S7 ((information seek* or ((find or finding) N2 information)) N5 11 (clinical or physician? or doctor? or bedside))

S6 ( (physician? or doctor? or clinician? or nurse or nurses) N4 ( 5 (information $\mathrm{n} 2$ retriev*$^{*}$ ) or (literature search*)) ) OR ( (portal N3 (physician? or doctor? or clinician?)) )

S5 ( ((find? w2 information) N12 (physician? or doctor? or clin- 3 ician?)) ) OR ( (portal N3 (physician? or doctor? or clinician? )) )

S4 ( ( information technology or wireless technology or PDA or 3 handheld or blackberr*) N10 (((clinical or physician? or doctor? or patient care) N2 (decision making)) or bedside)) ) OR ( ((access w2 evidence) N4 (physician? or doctor? or clinician? )) ) OR ( ((find\$ w1 information) N4 (physician? or doctor? or clinician?)) )

S3 ((information technology or wireless technology or PDA or 3 handheld or blackberr*) N10 (((clinical or physician? or doctor? or patient care) N2 (decision making)) or bedside))

S2 TI ( physician* AND information ) OR AB ( ((information seek* or searching or database* or electronic information or evidence-based information or evidence-based resource*) n5 
(clinician* or doctor* or practitioner* or nurse or nurses or allied health* or physician*)) )

S1 TI ( physician* or doctor* or clinician*) AND AB ( informa- 9 tion seek* or searching or database* ${ }^{*}$ or electronic information or evidence-based information or evidence-based resource* )

\section{Appendix 6. Protocol for Jousimaa 2002}

Primary care guidelines on consultation practices: the effectiveness of computerized versus paper-based versions. A cluster randomized controlled trial among newly qualified primary care physicians.

OBJECTIVE: To compare the effects of computerized versus paper-based versions of the same guidelines on recently qualified physicians' consultation practices

METHODS: Two arm cluster randomized controlled trial. All physicians licensed in Finland in 1998 will be contacted by phone. Eligible physicians include those who will work at least two months in a health centre between the study period from February 1998 to September 1999. The physicians will be randomized by computer-generated randomization number to receive either computerized or textbook-based versions of the same guidelines for a 4-week study period. Prior to the study the physicians will have at least one month's run-in period to get used to health centre work. Computers will be provided for the computer guideline group for the study period, if not available at workplace. Textbooks will be provided for the textbook guideline group. Physicians' compliance with guideline recommendations about laboratory, radiological, physical and other examinations, procedures, non-pharmacologic and pharmacologic treatments, physiotherapy, and referrals will be measured by case note review.

DATA ANALYSIS: Participating physicians are asked to identify, on a daily print-out of patient contacts, any consultation during which they have searched information to support patient care from any information source (information searching consultation). They are also asked to complete a brief questionnaire for each information search. Data will be collected for one month, or until a maximum of 50 information searching consultations are included.

The patient records are collected from information searching consultations and the preceeding consultations with a different patient which did not include information searches, and photocopied. Using this method, the physician will not know during the consultation, that the non-information seeking consultation is going to be analysed. All patient information data will be deleted from the photocopies in the health centre. The photocopies will be further mailed to an independent research centre, where the physician, health centre and study group will be anonymised. The anonymized record will then be evaluated by the three authors (JJ, IK, MM)* (SEE BELOW) and kappa statistics for concurrence will be calculated from a sample.

Nine elements will be evaluated: lab examinations, radiological examinations, physical examinations, other examinations for example, endoscopy, procedures, pharmacological treatments, non-pharmacological treatments, physiotherapy and referrals. Review criteria according to guidelines are developed for 99 commonest separate diagnoses, and the rest are evaluated case by case. Non-compliance with guidelines will be categorized as none, minor, major and serious.

STATISTICS. The physician is the unit of randomization and interference. The data will be analysed using adjusted Chi squared tests which account for the clustered nature of the data.

Actually this never happened, as the others were too busy to do the job. So, the judgement whether the participant followed the guideline was solely up to $\mathrm{JJ}$, but the criteria for commonest diagnoses were pre-defined by three authors (JJ, IIK, MM) and these diagnoses covered over $80 \%$ of cases

Interventions to increase the use of electronic health information by healthcare practitioners to improve clinical practice and patient 


\section{Appendix 7. Reviews screened for related references}

Gagnon M-P, Légaré F, Labrecque M, Frémont P, Pluye P, Gagnon J, et al. Interventions for promoting information and communication technologies adoption in healthcare professionals. Cochrane Database of Systematic Reviews 2009, Issue 1. Art. No.: CD006093. DOI: 10.1002/14651858.CD006093.pub2.

Weightman AL, Williamson J. The value and impact of information provided through library services for patient care: a systematic review. Health Information and Libraries Journal 2005;22(1):4-25. [PubMed: 15810928].

\section{Appendix 8. Authors contacted}

We contacted Campbell et al. to clarify error reported in the conference abstract of their study. We also requested, and received, an inpress manuscript containing further detail on the study interventions, and results.

We contacted Haynes to clarify the nature of the McMaster PLUS database and interface.

\section{Appendix 9. Translation}

PMID: 15565963 [Physicians' skills with evidence-based medicine. Concepts, information retrieval and use]. No English abstract in MEDLINE; received full-text (Danish). Sought translation from Sara Louise Klingenburg, Cochrane Hepato-biliary Group, who confirmed intervention and outcomes were not relevant; further, the study was clearly a questionnaire survey.

\section{Appendix 10. Healthcare quality improvement organizations (a sample)}

Institute for Healthcare Improvement www.ihi.org/Engage/Initiatives/SouthAfrica/Pages/default.aspx includes links for projects in Africa, Asia Pacific, Europe, Latin America, Middle East, and North America.

\section{WHAT'S NEW}

Last assessed as up-to-date: 13 November 2013.

\section{Date}

Event

11 March 2015 New citation required but conclusions have not changed

\section{Description}

Many new members in the author team, extensive rewriting, new methods used to assess the risk of bias and the quality of the evidence

Terminology changed for consistency and clarity: "electronic health information" is used to describe the type of information investigated in this review

The original title: "Electronic retrieval of health information by healthcare providers to improve practice and patient care" has been changed to reflect the preferred wording to describe the type of information under investigation

The term "retrieval" has been removed from the title in order to clarify the objectives of the review which are to examine practitioners "use" of information. The concept of "use" is different from the concept of "information retrieval" suggested by the original title. Informa- 
tion retrieval is a broader concept than information use; information retrieval includes assessment/evaluation of a user's searching skills in addition to "use" of information. Again, we believe this change clarifies the objectives of the review

Comparisons have been reworded as follows:

1. Revised: Electronic versus printed health information.

Original: Electronic retrieval of information compared to access to print based materials only

2. Revised: Health information via different electronic devices.

Original: Electronic retrieval of information compared to one or more other types of electronic retrieval of information

3. Revised: Health information via different user interfaces.

Original: Electronic retrieval of information compared to one or more other types of electronic retrieval of information

Original: Enhanced electronic retrieval of information compared to access to the electronic resource as part of standard practice

4. Added: Electronic health information combined with a training/educational component vs. no or other education

5. Revised: Electronic health information compared to no other type or source of information

Original: Electronic retrieval of information compared to no electronic retrieval (or no intervention) in practice

\section{H I S T O R Y}

Protocol first published: Issue 2, 2004

Review first published: Issue 3, 2009

\begin{tabular}{l|l|l}
\hline Date & Event & Description \\
\hline 10 October 2013 & Amended & Added CBAs and NRCTs to acceptable included studies. \\
\hline 17 February 2010 & Amended & Changed author information \\
\hline 12 February 2004 & New citation required and major changes & Substantive amendment \\
\hline
\end{tabular}

Interventions to increase the use of electronic health information by healthcare practitioners to improve clinical practice and patient 


\section{CONTRIBUTIONSOFAUTHORS}

Manuscript, data extraction: MF, PP, RG, KH, ML, JM, DS.

Screening: MF, GF, SS, MF, PP, RG, KH, ML, JM, DS.

Search strategy development and information management: NR, MF.

\section{DECLARATIONSOF INTEREST}

None known.

\section{SOURCES OF SUPPORT}

\section{Internal sources}

- Institute of Population Health, University of Ottawa, Canada.

- Belgian Centre for Evidence-Based Medicine, Belgium.

- Department of Family Medicine, McGill University, Canada.

- Department of Family Medicine, Laval University, Canada.

\section{External sources}

- Canadian Institutes of Health Research, Post-doctoral Fellowship grant, Canada.

- Fonds de la recherche en santé du Québec, Canada.

- UK NHS Cochrane Collaboration Programme Grant Scheme, United Kingdom, Other.

\section{DIFFERENCES BETWEEN PROTOCOLAND REVIEW}

- We used a new, highly sensitive search strategy without date or language limits in an effort to be exhaustive in identifying studies comparing electronic with other formats of health information. We made a decision to consider a practitioner's logins to EHI as a measure of practitioner behavior/professional practice.

- We have changed the terminology for consistency: we used electronic health information or EHI to describe the type of information investigated in this review.

- We changed a portion of the title from "electronic retrieval of health information" to "use of electronic health information." This change has been made for two reasons.

○ The concept of "information retrieval" is broader than "information use." Information retrieval as a science typically involves assessment of searching skill, search query development, and analysis of "information needs." Thus, references in the review to the "retrieval" of electronic information introduced unnecessary complexity. This review examined practitioners' use of information; it did not seek to evaluate searching skills, search query development, or information needs.

- To improve clarity, we decided to describe the information as electronic as opposed to describing the retrieval process as electronic. Our rationale was that any information obtained on a computer or via a network was, de facto, electronic, and that the "retrieval" process, was, as stated above, out of scope of this review.

Interventions to increase the use of electronic health information by healthcare practitioners to improve clinical practice and patient 